\title{
Factors associated with treatment acceptance and compliance among incarcerated male sex offenders
}

\author{
Carl B. Clegg \\ West Virginia University
}

Follow this and additional works at: https://researchrepository.wvu.edu/etd

\section{Recommended Citation}

Clegg, Carl B., "Factors associated with treatment acceptance and compliance among incarcerated male sex offenders" (2009). Graduate Theses, Dissertations, and Problem Reports. 2880.

https://researchrepository.wvu.edu/etd/2880

This Dissertation is protected by copyright and/or related rights. It has been brought to you by the The Research Repository @ WVU with permission from the rights-holder(s). You are free to use this Dissertation in any way that is permitted by the copyright and related rights legislation that applies to your use. For other uses you must obtain permission from the rights-holder(s) directly, unless additional rights are indicated by a Creative Commons license in the record and/ or on the work itself. This Dissertation has been accepted for inclusion in WVU Graduate Theses, Dissertations, and Problem Reports collection by an authorized administrator of The Research Repository @ WVU.

For more information, please contact researchrepository@mail.wvu.edu. 
Factors Associated with Treatment Acceptance and Compliance Among Incarcerated Male Sex Offenders

\title{
Carl B. Clegg
}

\author{
Dissertation submitted to the \\ College of Arts and Sciences \\ at West Virginia University \\ in partial fulfillment of the requirements \\ for the degree of \\ Doctor of Philosophy \\ in \\ Clinical Psychology
}

\author{
William Fremouw, Ph.D., Chair \\ Barry Edelstein, Ph.D. \\ Kevin Larkin, Ph.D. \\ Neil Mogge, Ph.D. \\ Michael Perone, Ph.D. \\ Department of Psychology
}

Morgantown, West Virginia

2009

Keywords: sex offenders, sex offender treatment, treatment compliance, incarceration 


\begin{abstract}
Factors Associated with Treatment Acceptance and Compliance Among Incarcerated Male Sex Offenders

Carl B. Clegg
\end{abstract}

The present study examined factors associated with acceptance and completion of treatment among incarcerated male sex offenders. The files of 156 sex offenders who had been offered treatment at a medium-security state prison were reviewed. Participants were divided into three groups: those who refused treatment from the outset $(n=59)$; those who began treatment, but later dropped-out or were expelled due to non-compliance $(n=61)$; and those who completed treatment or were in an advanced stage of treatment and had never been non-compliant $(n=36)$. Data were collected for the following variables: age, education, race, marital status, plea, offense denial, parole eligibility, victim age, victim gender, relation to victim, prior sexual offenses, prior felony incarcerations, psychiatric disorders, mental health treatment, childhood sexual victimization, IQ, reading ability, neurological impairment, and personality assessment scores. Significant differences were found between groups on years to parole eligibility; plea; relation to victim; childhood sexual victimization; and MMPI-2 VRIN, L, and Mf scale scores. Logistic regression analyses revealed that significant predictors of treatment refusal include: increased time until parole eligibility and lower VRIN and Mf scores (vs. non-compliant), and no history of childhood sexual victimization and higher L scores (vs. compliant). Having entered a not guilty plea was the only significant predictor of non-compliance among those who initially accepted treatment. These findings are discussed in relation to previous studies of sex offender treatment compliance and directions for future research. 


\section{Acknowledgements}

There are a number of people who made the successful completion of this dissertation possible. First and foremost is my committee chair, Dr. William Fremouw. His tremendous knowledge, experience, and practical advice helped make my entire graduate career more productive and enjoyable than it probably would have been otherwise. I would also like to thank my other committee members, Dr. Barry Edelstein, Dr. Kevin Larkin, Dr. Neil Mogge, and Dr. Michael Perone, for their time and useful suggestions. A very special thanks goes to Dr. Thomas Horacek and Angel Cole for making the necessary arrangements for this study to be completed, and to fellow graduate student Rebecca Schwartz for assisting in data collection. Lastly, I would like to thank my wife Courtnie and my children, Alexandra and Kenneth, for making it all worthwhile. 


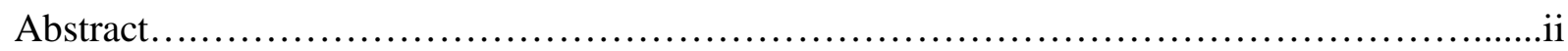

Acknowledgements.................................................................

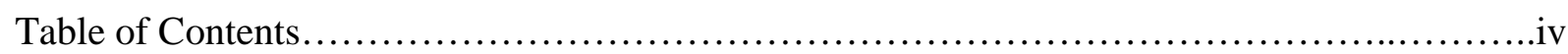

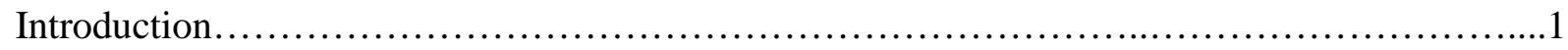

Limitations in Sex Offender Treatment Research..................................1

Treatment Compliance Research.............................................. 2

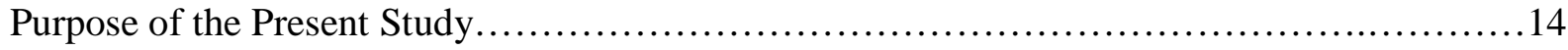

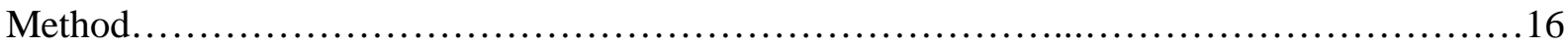

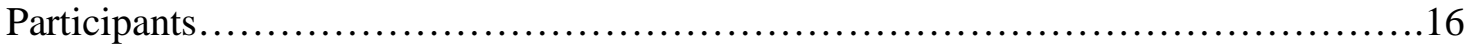

Measures...................................................................... 18

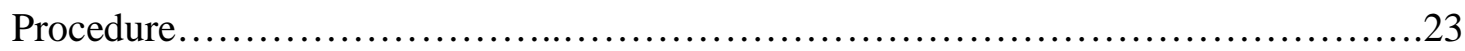

Results............................................................................ 25

Preliminary Analyses.................................................... 25

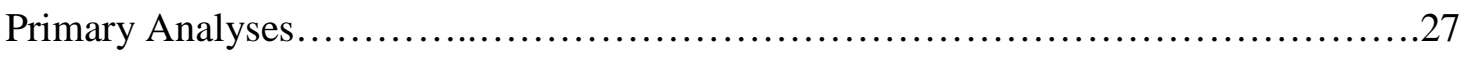

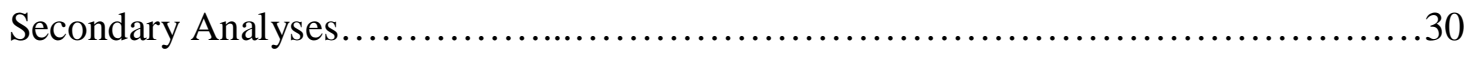

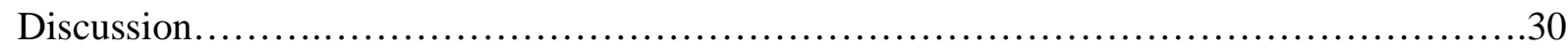

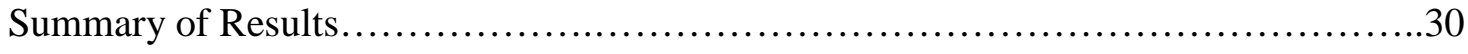

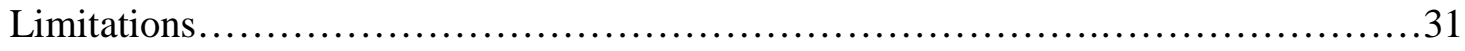

Directions for Future Research............................................... 33

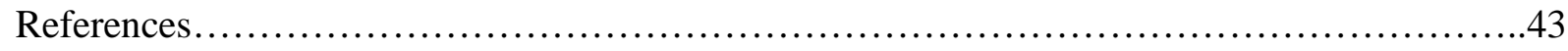

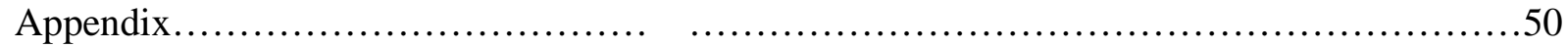


Tables. .55

Table 1 (Definitions of the study variables and interrater agreement)..... .55

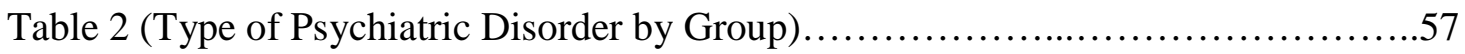

Table 3 (Demographic Variables by Group)........................................58

Table 4 (Offense Variables by Group) ......................................5

Table 5 (Clinical Variables by Group)........................................61

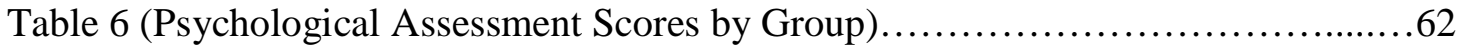

Table 7 (Logistic Regression Prediction of Refusal versus Non-Compliance)............65

Table 8 (Logistic Regression Prediction of Refusal versus Compliance).................66

Table 9 (Logistic Regression Prediction of Non-Compliance versus Compliance).......67

Table 10 (Correlations Among Study Variables).................................68 
Factors Associated with Treatment Acceptance and Compliance Among Incarcerated Male Sex Offenders

On any given day in the United States there are approximately 234,000 individuals convicted of a sexual offense under the care, custody, or control of corrections agencies (Bureau of Justice Statistics, 2007), and it is widely accepted that only a small proportion of sexual offenses result in convictions (Kalichman, Shealy, \& Craig, 1990). Increased awareness of the enormous financial and psychological costs on victims and on society has resulted in a tremendous amount of research in recent decades regarding how to best address the problem of sexual offending. Many mental health professionals have conceptualized sex offenders as having psychological disorders that are amenable to assessment and treatment (Rice \& Harris, 2003). There have been numerous published reviews of the effectiveness of treatment for sex offenders since 1980 (Collaborative Outcome Data Committee [CODC], 2007). Cognitive-behavioral approaches to treatment are most commonly employed (Craig, Brown, \& Stringer, 2003) and there is some modest evidence of their usefulness with sex offenders (Losel $\&$ Schmucker, 2006). However, no strong conclusions have been made because all reviews have noted significant limitations in most of the available studies.

\section{Limitations in Sex Offender Treatment Research}

All approaches to sex offender management, be it interventions (e.g., psychological or pharmacological treatment) or legislation (e.g., community notification, registration, civil commitment) share a common paramount goal to prevent, or, at least, diminish the likelihood of, sex offenders committing future sexual offenses. Therefore, unlike many other treatments that tend to be more egocentric, sex offender treatment tends to be more sociocentric (i.e., successful treatment is defined more by improvement within the community than improvement in the 
mental health status of the individual). Also, in contrast to other psychological treatment programs of potentially repetitive or addictive behaviors (e.g., substance abuse) where some relapse may be expected, the recommission of a sexual offense is not tolerable (Hall \& Nagayama, 1995). Although reconviction for any sexual offense is the most common measure of recidivism for sex offenders, there are different operational definitions of recidivism used in the literature (Barnes et al., 1994). First, reoffense can be measured by reincarceration (imprisonment), reconviction (adjudicated guilty), or recommission (e.g., arrests, self-report). To complicate matters, all three of these measurement methods can include committing the same type of sexual offense, any sexual offense, any violent offense, or simply any criminal offense (even if it is not sexual or violent). Self-report is of dubious validity so only official legal records are typically used, but this approach likely underestimates the actual number of sexual offenses (Craig et al., 2003). Also, even after an arrest has been made it does not always lead to a conviction for the alleged sexual offense due to the possibility of an acquittal or acceptance of a plea bargain to a lesser (often non-sexual) offense.

Perhaps the greatest difficulty with the use of recidivism data to measure treatment success is that failure is not usually observed in treatment and may not be noticed until years afterward (Doren, 1998). Contrary to the assumptions of many, the base rates of reconviction for a sexual offense are lower than for many other offenses (e.g., drug related, non-sexual violent) (Aytes, Olsen, Zakrajsek, Murray, \& Ireson, 2001). Even chronic or habitual sexual offenders may have several years of not being detected for illegal behavior. In fact, the majority of sex offenders who eventually reoffend are not convicted within 3-5 years of their release from prison (Barnes et al., 1994). An extensive follow-up period with a large sample is usually not feasible, but may be required to have sufficient statistical power to detect treatment effects. 
Another significant limitation in sex offender treatment research is legal or ethical constraints that preclude the use of random assignment to a no-treatment, or an ostensibly less effective treatment, control group. First of all, it is legislatively mandated in many jurisdictions that sex offenders receive treatment (sometimes a specifically designated type of treatment) (Marques, Day, Nelson, \& West, 1994). Secondly, there are ethical concerns about excluding individuals who may be dangerous to society from receiving the treatment that is most likely to be beneficial (CODC, 2007). There is often difficulty in comparing results from different jurisdictions and time periods due to the differences in legal mandates regarding treatment and legal definitions of certain sexual offenses (e.g., age of consent).

Many sex offender treatment researchers have suggested that certain subtypes of sex offenders (e.g., rapists) may be less amenable to treatment and a greater risk for recidivism than others (Hanson, 2000). Additionally, some researchers have commented on the further heterogeneity within sex offender subtypes (e.g., incest vs. extrafamilial pedophiles) (Robertiello $\&$ Terry, 2007). A common theme in most proposed classification schemes is the idea of at least one type of sex offender that essentially prefers deviant/illicit sex to consensual sex (e.g., paraphilic, preferential) versus those who do not (e.g., antisocial, opportunistic) (Lalumiere, Quinsey, Harris, Rice, \& Trautrimas, 2003). Not surprisingly, Maletzky and Steinhauser (2002) found that preferential offenders have higher rates of recidivism than opportunistic offenders. Distinguishing between these subtypes is likely to have important treatment implications. For example, reducing or changing sexual fantasies and sexual behavior may be more important for paraphilic/preferential sex offenders, while reducing anger, stress, or substance abuse may be more important for antisocial/opportunistic sex offenders (Seto \& Kuban, 1996). 
An area of research that is relevant in addressing these limitations, but has received relatively little attention in the sex offender literature, is treatment compliance. Langevin (2006a) has found the majority $(58 \%)$ of sex offenders never attend treatment and the majority $(68 \%)$ of those who begin treatment do not complete it. Many researchers have found that offenders who refuse or prematurely end treatment (e.g., expelled, drop-out) are at a higher risk for recidivism than those who complete treatment. However, there are few published reports on the characteristics of these two groups. It is possible that pre-treatment differences between them are the primary explanation for the differing rates of recidivism. Therefore, a treatment sample at the conclusion of a study may provide biased positive results for treatment effectiveness. The findings of studies that have high rates of attrition or do not track drop-outs can be used (if applicable) as evidence of the lack of treatment effectiveness, but they should not be used as evidence in favor of treatment effectiveness (Rice \& Harris, 2003). Also, a large proportion of sex offender treatment is administered in prison. Limited resources in correctional treatment programs sometimes preclude a significant percentage of non-incarcerated offenders who desire treatment from receiving it (Shaw, Herkov, \& Greer, 1995). Thus, being able to identify those who are most likely to benefit from treatment is imperative. The impact of incarceration on amenability to treatment is unclear. For instance, incarceration may increase the willingness of some offenders to comply with treatment (e.g., perceived increased chance for parole) whereas it may decrease the willingness of others (e.g., perceived repercussions from other inmates).

The following section provides a review of the sex offender treatment compliance research literature. Eleven studies have been identified; six using non-incarcerated participant samples (Craissati \& Beech, 2004; Craissati \& McClurg, 1997; Hunter \& Figueredo, 1999; Langevin, 2006a; Levenson \& Macgowan, 2004; Miner \& Dwyer, 1995) and five using 
incarcerated participant samples (Caperton, Edens, \& Johnson, 2004; Geer, Becker, Gray, \& Krauss, 2001; Kalichman et al., 1990; Moore, Bergman, \& Knox, 1999; Shaw et al., 1995). The findings and limitations of these studies are then summarized and discussed in connection with the present study.

\section{Treatment Compliance Research}

\section{Non-Incarcerated Samples}

Miner and Dwyer (1995) used archival records from 1977 to 1992 at a university-based outpatient sex offender treatment program to examine what psychological characteristics are related to completion of treatment. They identified 173 offenders who completed both the Minnesota Multiphasic Personality Inventory (MMPI; Hathaway \& McKinley, 1940) and the Tennessee Self-Concept Scale (Roid \& Fitts, 1991) at intake into the program. Seventy-nine of these offenders completed treatment while the other 94 did not. In contrast to an objective criterion (e.g., attendance), treatment completion reflected the consensus of the clinical staff that a "subject had adequately addressed the program goals and resolved his specific treatment issues such that the risk of committing a new sex offense was minimal” (p. 81). They found that not being married, lower income, lower Tennessee Self-Concept scores, and lower MMPI L and K scale scores were associated with not completing treatment. Furthermore they found exhibitionists were less likely to complete treatment than incest offenders, extrafamilial child molesters, and other (not specified) offenders. No significant differences were found for age, education, or number of previous sex offenses.

Craissati and McClurg (1997) compared the outcomes of individual versus group cognitive-behavioral therapy (both administered by the same treatment program in England) on recidivism and several psychological measures at one and two year follow-ups. During the time 
period of the study, all convicted child molesters in southeast London who were deemed appropriate for community treatment by a court or parole board were referred to this program. As part of their analyses, they also examined characteristics associated with treatment compliance, which was defined as: not being reconvicted for any offense during treatment or the two year follow-up period, not being expelled or dropping-out for any reason, and not missing more than two sessions during the course of the treatment. They found no difference in compliance for treatment condition (i.e., individual vs. group therapy). However, they did find that a history of childhood sexual victimization, a history of previous sexual and/or violent offending, high levels of cognitive distortions (as measured by the Abel and Becker Cognitions scale [Abel, Becker, Cunningham-Rathner, 1984]), chronic substance abuse, and extrafamilial sexual offending were associated with increased treatment non-compliance. Variables measured, but not significantly associated with treatment compliance, included: age; IQ (as measured by the Wechsler Adult Intelligence Scale-Revised [WAIS-R; Wechsler, 1981]); victim gender; and scores on the Multiphasic Sex Inventory (MSI; Nichols \& Molinder, 1984), Fear of Negative Evaluation Scale (FNE; Leary, 1983), Buss Durkee Hostility Inventory (BDHI; Buss \& Durkee, 1957), and Attitudes Towards Women scale (ATW; Spence, Helmreich, \& Stapp, 1973).

Craissati and Beech $(2004)$ compared rapists $(n=80)$ to child molesters $(n=230)$ on background, offense, and treatment-related variables among offenders referred to the Challenge Project previously described. They found that rapists were significantly more likely to be in total denial (as opposed to partial denial or full acceptance) to their crime than child molesters. Rapists were less likely to have had any previous treatment and were less likely to participate in the present treatment program. An examination of those who did participate in treatment (23 rapists, 106 child molesters) revealed a non-significant trend towards improved treatment 
compliance for child molesters. Treatment compliance was defined as not dropping-out or leaving the program for any reason, and missing no more than one treatment session. It was reported that rapists only included those who offended against adults. Therefore it is possible that a significant percentage of those in the child molester sample offended against post-pubescent females.

Hunter and Figueredo (1999) examined factors associated with treatment compliance among juvenile sex offenders in a community-based alternative treatment. Of the 204 male youths assessed, $85.7 \%$ were court adjudicated (or advised) to receive treatment while the other $14.3 \%$ participated without court involvement. The reference offense was child molestation (> 2 years older than victim) for $76 \%$ of the cases, rape (younger or $<3$ years older than victim) for $8.8 \%$ of the cases, exhibitionism for $2.9 \%$ of the cases, and miscellaneous (e.g., frotteurism) for $12 \%$ of the cases. They found that youths who were expelled or dropped-out of treatment had higher levels of sexual maladjustment (as measured by MSI) and were more likely to deny their crimes than those who successfully completed or remained in treatment after 12 months. As they expected, those youths who had already been fully adjudicated by the court were less likely to deny their crime, and, thus, were more compliant with treatment. However, contrary to expectations, denial did not appear to be related to general psychological defensiveness or antisocial behavior (as measured by the MMPI L and Pd scales, respectively). Differences in treatment compliance by type of sexual offense were not reported.

Levenson and Macgowan (2004) examined the relation between engagement, denial, and treatment progress among 61 male sex offenders. Although they did not examine treatment compliance per se, denial typically precludes admission to or completion of sex offender treatment. Therefore, admitting to the commission of a sexual offense, and/or admitting to a 
sexual disorder, is an integral component of treatment compliance (Association for the Treatment of Sexual Abusers [ATSA], 2001). For the majority of participants, attendance in the program was a requirement of probation following a conviction for a sexual offense. Treatment progress was measured with the Sex Offender Treatment Rating Scale (SOTRS; Anderson, Gibeau, \& D’Amora, 1995), which is completed by the therapist and has items covering six dimensions: insight, deviant thoughts, awareness of situational risks, motivation, victim empathy, and offense disclosure. Engagement was measured with the Group Engagement Measure (GEM; Macgowan, 2000), which is completed by the client and covers seven dimensions: attending, contributing, interacting with the group leader, interacting with others in the group, agreeing with the policies/activities of the group, working on individual problems, and helping other group members work out their problems. Denial was conceptualized as a continuous (e.g., minimization), rather than dichotomous, variable and was measured with the Facets of Sexual Offender Denial scale (FoSOD; Schneider \& Wright, 2001). The FoSOD is completed by the client and covers six dimensions: refutation of the offense, denial of extent, denial of intent, assertion of victim desire, denial of planning, and denial of risk relapse. As expected, Levenson and Macgowan found that engagement was strongly correlated with treatment progress $(r=.72)$ and that denial had a strong inverse relation to both treatment progress $(r=-.63)$ and engagement $(r=-.50)$.

More recently, Langevin (2006a) conducted an extensive archival records study that examined the demographic and clinical differences between three non-mutually exclusive groups of sex offenders: those who expressed a desire for treatment (accept), those who had some treatment attendance (attend), and those who completed at least one course of therapy (complete). His sample consisted of male offenders assessed from the 1960s to the 2000s in 
Canada at either a university hospital or private clinic and included: 70 exhibitionists, 323 extrafamilial child molesters, 128 men with courtship disorder (i.e., convicted of rape or a combination of voyeurism, exhibitionism, and/or sexual assault), 219 incest offenders, and 21 mixed offenders (adult and child victims). Victims were defined as an adult if they were 16 years or older and as a child if they were under 16. Legal status was $46.4 \%$ pretrial, $13.6 \%$ presentence, $16.8 \%$ probation/parole, $8.2 \%$ no charges on condition of seeking treatment, and 14.9\% miscellaneous/unknown. Acceptance of treatment was based on client self-report of whether or not they wanted treatment (without being given any description of available treatments) when queried by the clinician at the time of their initial assessment. It was dichotomized as yes or no, with no attempt made to evaluate the sincerity of the response. Treatment attendance and completion were also dichotomized as yes or no and were based on hospital records and discharge information.

The following is a summary of Langevin's (2006a) findings. Acceptance, attendance, and completion of treatment have all progressively declined over the decades (except for increased treatment completion in the 1980s over the 1970s). Offenders who denied guilt for their charges and/or denied having a sexual problem were less likely to accept and attend treatment than those who did not deny such behavior. Younger offenders were more likely to accept and attend treatment than older offenders. Those who were less educated or had never been married were more likely to attend treatment than those who had more education or had ever been married. Offenders with no legal charges were more likely to accept, attend, and complete treatment than those with legal charges. Those who were awaiting sentencing were less likely to attend and complete treatment, whereas those awaiting trial were less likely to accept treatment, than the other legal status groups. Recidivists (those who had a previous sexual offense conviction) were 
more likely to accept and attend treatment than non-recidivists. Offenders who had previously been incarcerated were more likely to accept treatment than those who had never been incarcerated. Exhibitionists were more likely, and incest offenders were less likely, to accept treatment than the other offender subtypes. Those who were deemed sexually deviant on phallometric testing (specific criteria not given) were more likely to attend treatment than those deemed non-deviant. Individuals diagnosed with drug abuse or antisocial personality (and/or higher scores on the Psychopathy Checklist-Revised [PCL-R; Hare, 2003]) disorders, based on Diagnostic and Statistical Manual of Mental Disorders (DSM-IV-TR; American Psychiatric Association [APA], 2000) criteria, were more likely to accept and attend treatment, but were less likely to complete treatment, than those without these disorders. Those who had been diagnosed with Attention Deficit-Hyperactivity Disorder (ADHD), ever failed a grade or placed in special education classes at school, or were ever rendered unconscious were more likely to accept and attend treatment than those who never experienced these problems potentially indicative of neurological impairment. Psychosis, alcohol abuse, and IQ scores were also examined, but no significant differences were found.

\section{Incarcerated Samples}

Kalichman et al. (1990) were the first to explore the clinical utility of the MMPI in sex offender treatment. Their sample consisted of 55 incarcerated rapists (convicted of sexually assaulting at least one adult woman and no criminal history of sexually assaulting children) who voluntarily attended weekly group treatment sessions. They examined scores on the 3 primary validity scales (i.e., F, L, K) and the 10 clinical scales (Hs, D, Hy, Pd, Mf, Pa, Pt, Sc, Ma, Si) of the MMPI, treatment attendance (percentage of sessions attended), and treatment participation (based on the treatment staff's rating of participants on 5-point Likert type scales that measured 
communication skills, group cohesion, risk taking, self-disclosure, and self-expression). Stepwise regression analyses revealed that the higher $\mathrm{F}, \mathrm{Ma}$, and $\mathrm{Pa}$ scores, and lower $\mathrm{K}$ scores significantly predicted increased treatment attendance (accounting for $18 \%$ of the variance) whereas higher $\mathrm{K}$ and L scores and lower $\mathrm{Hy}, \mathrm{Mf}$, and Pd scores significantly predicted increased level of participation (accounting for $24 \%$ of the variance). These findings suggest that rapists who present greater levels of psychopathology (particularly affective and thought disorders) on psychological tests are more likely to attend treatment programs. Ironically, however, offenders who likely responded to test items in a guarded manner and attempted to portray themselves in an overly favorable light (i.e., higher K scores) were seen as more open and cooperative by the clinicians.

Shaw et al. (1995) examined whether factors previously found to be predictive of treatment completion in outpatient samples would be equally predictive in an incarcerated sample. They compared the reading ability, age, marital status, presence of antisocial personality, and type of offense (i.e., incest, child molestation, rape [age of victims not mentioned]) of sex offenders who successfully completed treatment $(n=16)$ versus those who did not (e.g., dropped out, rejected from treatment for unwillingness to actively participate and/or admit to their offense) $(n=98)$. They found that treatment completers had significantly higher reading ability (as measured by the Wide Range of Achievement Test - Revised [WRAT-R; Jastak \& Wilkinson, 1984]) and were more likely to be married than non-completers. No significant differences were found for the other variables, and the authors suggest several reasons why. For instance, incarcerated offenders are more likely to have committed multiple and/or violent offenses. Thus, they may represent a more disturbed and recalcitrant group than non-incarcerated offenders in which age and type of offense are not important variables. They also note the high 
base rate of antisocial personality among incarcerated offenders may preclude it from being a discriminating variable in this population. Additionally, the size of the completion sample was small and included only seven non-incest offenders.

Moore et al. (1999) examined which demographic, offense, and psychological variables were predictive of completion of a prison-based sex offender treatment program. Their sample included 126 offenders who requested to participate in treatment. They do not report type of offense, but the variable of victim age was categorized into four groups $(0-5,6-12,13-17,18+)$. A linear discriminant function analysis revealed that ever being married, being diagnosed with a substance abuse disorder, not being diagnosed with Antisocial Personality Disorder, not having a history of violent offenses, and not having victims in the two highest age groups were predictive of increased treatment completion (accounting for $11 \%$ of the variance and correctly classifying $73 \%$ of offenders). Age (offender), education, race, a diagnosis of pedophilia, other previous substance or sexual offenses, gender of victim, relation to victim (stranger, acquaintance, family member), and use of force in the instant offense (criteria not given) were not predictive of treatment completion. The authors note that a substance use disorder may not have a negative impact on treatment compliance in prison, in contrast to outpatient settings, due to the relative unavailability of drugs and alcohol.

Geer et al. (2001) examined how well psychological and physiological tests predicted treatment completion among incarcerated sex offenders. Their sample consisted of 179 male sex offenders who voluntarily participated in treatment. Completers were defined as those who attended the sessions and completed the post-tests at satisfactory levels. Non-completers are those who were terminated from the program due to voluntary withdrawal, lack of attendance or participation, parole, or institutional misconduct. Measures included the Multiphasic Sex 
Inventory II (MSI II; Nichols \& Molinder, 1996), the MMPI L, K, F, and Pd scales, the Abel and Becker Adult Sexual Interest Card Sort (Abel \& Becker, 1985), and plethysmography. They found that treatment completers were more likely to have a higher education level, no history of being sexually abused as a child, fewer previous incarcerations, lower scores on the MSI II Lie and Denier scales, lower scores on the MMPI L and Pd scales, and higher maximum appropriate stimuli scores on the card sort than non-completers. Hierarchical logistic regression analysis revealed that more years of education, no history of being sexually abused as a child, fewer previous incarcerations, and lower scores on the MSI II Denier scale were predictive of treatment completion. The authors hypothesize the reason offenders who were sexually abused as children were less likely to complete treatment is because they do not consider their behavior to be deviant and/or they are uncomfortable bringing up traumatic memories.

Caperton et al. (2004) examined the utility of the Personality Assessment Inventory (PAI; Morey, 1991) in identifying inmates who were prone to engaging in institutional misconduct. Specifically they examined the correlations between the Antisocial Features scale (ANT), Aggression scale (AGG), Violence Potential Index (VPI), and the Treatment Rejection scale (RXR). Their sample included 137 inmates in a mandated sex offender treatment program. Infractions were categorized into three broad categories: physical aggression (e.g., assaulting an officer), verbal aggression/acts of defiance (e.g., threatening an officer), and non-aggressive infractions (e.g., gambling). Additionally, they examined sex offender treatment non-compliance (i.e., lying to treatment staff, refusing to attend treatment sessions, failing to complete assignments, being disrespectful to group members) and sexual misconduct infractions (i.e., engaging in sexual acts with others, soliciting sexual acts from others, masturbating in public). There was a significant positive correlation between treatment non-compliance and the 
RXR scale. The other PAI scales were not correlated with treatment non-compliance or sexual misconduct. Because treatment was not voluntary the base rate of non-compliance was low (10\%). Also, 59\% of offenders scored above the suggested cut score (i.e., > 43) on the RXR scale. Thus, the RXR scale had very poor positive predictive power $(\mathrm{PPP}=.15)$ in correctly classifying compliant versus non-compliant offenders. Although the authors suggest the PAI may help identify offenders who are more likely to be non-compliant with treatment, they recommend no particular cut-off scores in making this determination.

\section{Summary}

Twenty-one different types of variables were examined in the above studies, 15 were included in more than one study (i.e., marital status, education, age, recidivism, type of sexual offense, violence during the offense, victim age, victim gender, substance abuse, intellectual ability, cognitions/attitudes/personality, psychological disorders, previous incarcerations, offense denial, and childhood sexual victimization) and 6 were limited to one study (i.e., income, race, previous sex offender treatment, mode of therapy, adjudication status, and potential neurological impairment). The only variables found to be significantly associated with treatment completion in more than one study were: marital status, age of victim, psychological disorders, offense denial, and childhood sexual victimization. Specifically, treatment completers are more likely to have been married, have child victims, admit their crime, and not have Antisocial Personality Disorder or a history of being sexually abused as a child. With the exception of Langevin (2006a; outpatient sample), none of the studies examined the characteristics of sex offenders who refuse treatment from the outset.

\section{Purpose of the Present Study}

In addition to potentially replicating and validating many of the findings from previous 
research on sex offender treatment compliance, the present study makes a unique contribution to the literature in several ways. First and foremost, this study compared the characteristics of incarcerated male sex offenders who refused treatment from the outset to those both those who become non-compliant with treatment and those who remain compliant with treatment. Second, this study examined the differences between these groups on: the Restructured Clinical [RC] scales and the TRT (Negative Treatment Indicators) content scale of the MMPI-2, a screening assessment for neurological deficits (Trail Making Test; Reitan, 1958), mental health treatment, and the adjudication variables of plea entered and years to parole eligibility. Third, it examined the variables of offense admission and IQ score in an incarcerated sex offender sample. The other variables included, but not unique to this study, are: age, race, education, marital status, violence during the offense, victim age, victim gender, relation to victim, reading ability, psychiatric disorders, prior felony incarcerations, reported childhood sexual victimization, and MMPI-2 validity and clinical scale scores.

Although not previously examined in the sex offender treatment compliance literature, length of time until parole eligibility was included because it very likely could impact an inmate's motivation to obtain treatment (Caperton et al., 2004). Plea entered was examined because it was conceptualized to be related to offense denial and compliance in general. As will be more fully explained in the measures section, the Trail Making Test serves as a screening measure for potential neurological problems. In addition to the findings of potential neurological impairment in Langevin (2006a), Langevin (2006b) found almost half of a sample of 476 male sex offenders had sustained head injuries rendering them unconscious and more than one-fifth had sustained significant neurological insults prior to committing their sexual offense. It is possible that neurological deficits have an impact on willingness and ability to comply with 
treatment. In addition to $\mathrm{L}, \mathrm{K}$, and F, the newer MMPI-2 validity scales (i.e., VRIN, TRIN, Fb, Fp, FBS, S) were also included because response style on an assessment measure may be indicative of response style in treatment (e.g., minimize or exaggerate problems). The Restructured Clinical Scales of the MMPI-2 were examined along with the traditional clinical scales because they have been designed to have less item overlap and greater discriminant validity (Tellegen et al., 2003). The Negative Treatment Indicators (TRT) content scale of the MMPI-2 was also included because high scores are specifically indicative of behaviors associated with poor treatment compliance and prognosis (Graham, 2006). Mental health history was also examined because many researchers have suggested that psychological problems are likely associated with sex offender treatment compliance, yet surprisingly little has been done to examine this hypothesis. IQ scores and offense admission were included to see if findings among non-incarcerated samples can be generalized to incarcerated offenders. The rationale for the inclusion of the remaining variables is that they have been suggested in the research literature as being relevant to sex offender treatment compliance and the information needed to examine them was deemed likely to be available in the legal files reviewed for this study (based on consultation with prison psychology staff).

Method

\section{Participants}

The participant database was obtained through file reviews at Huttonsville Correctional Center (HCC) in Huttonsville, West Virginia. HCC is medium-security state prison that houses over 1200 male prisoners for a variety of offenses. At the time of data collection, there were 229 inmates who had been convicted of a sexual crime. A sex offender group treatment program (cognitive-behavioral) that consists of three phases is run by a staff psychologist. Typically any 
inmate who has been convicted of s sexual crime is eligible to attend. However, at any given time, a large percentage of those who are eligible have not been offered treatment for various reasons (e.g., recent admission, imminent transfer/discharge/parole). Although participation is voluntary there are potential incentives for doing so (e.g., lower classification score that may result in increased inmate privileges within the prison, improved chance for parole). At the time of data analysis, 156 inmates had been offered participation in the current treatment program (i.e., since January 2007) at least once and were included in this study. They were separated into three groups: those who had never accepted treatment $(n=59)$; those who had attended treatment at least once, but dropped-out or were expelled due to non-compliance $(n=61)$; and those who had completed Phase I treatment and were currently compliant with an advanced phase of treatment $(n=36)$.

\section{Description of Treatment Phases}

Phase I. The first phase of treatment covers educational content in weekly, one hour sessions over the course of 10-12 weeks. The optional two extra sessions allows for additional work on program content as needed. The specific topics include: West Virginia sexual offense laws, registry requirements, victim impact, cognitive distortions, anger management, patterns of deviant behavior, and an introduction to the concept of empathy. All sexual offenders are referred to Phase I treatment regardless of whether they admit or deny their crime or report any other sexually deviant behavior.

Phase II. The second phase of treatment also consists of weekly, one hour sessions. However, there is flexibility in the content and the number of these sessions based on the needs of the group. This program covers the issues introduced in Phase I in more depth as well as sexually deviant issues that are more specific to each individual offender. In general, offenders 
must admit their crime in order to enroll in this phase of treatment because they must be able to identify some form of social/sexual deviance which the program would likely be able to address with them.

Phase III. The final phase of treatment provides weekly, one hour sessions designed to assist the offender make a successful integration back into society. Therefore, it is recommended that the offender enter this program when they are within six months of discharge or during the holding period after they have been granted parole. The offender in this phase may also be encouraged to continue to participate in Phase II treatment concurrently. The framework for this program is largely based on the relapse prevention $\operatorname{model}^{1}$ (Pithers, Marques, Gibat, \& Marlatt, 1983) of sex offender treatment. According to this model, it is important to identify and avoid situations that may eventually lead to a high-risk of reoffending (Polaschek, 2003).

\section{Measures}

Minnesota Multiphasic Personality Inventory-2 (MMPI-2). The MMPI-2 (Butcher, Williams, Graham, Tellegen, \& Kaemer, 1989) is a revised version of the original MMPI (Hathaway \& McKinley, 1940) and is the most widely used personality test in the United States and the world (Graham, 2006). The MMPI was the first personality test to use an empirical, rather than theoretical, keying approach wherein test items did not necessarily have face validity, yet were found to discriminate between known groups. The MMPI-2 contains 567 statements to which respondents answer either true or false if it applies to them. It is designed for use with individuals 18 years and older with at least a sixth-grade reading level. It contains 10 clinical scales that assess various facets of personality and psychopathology: Social Introversion ( $\mathrm{Si}$ ), Hypochondriasis (Hs), Depression (D), Hysteria (Hy), Psychopathic Deviate (Pd), 
Masculinity-Femininity (Mf), Paranoia (Pa), Psychasthenia (Pt), Schizophrenia (Sc), and Hypomania (Ma). These scales are often referred to by the numbers $0-9$, respectively. It also contains nine validity scales that assess the likelihood of honest and consistent responding: Variable Response Inconsistency (VRIN), True Response Inconsistency (TRIN), Infrequency (F), Back Infrequency (Fb), Infrequency Psychopathology (Fp), Fake-Bad Scale (FBS), Lie (L), Correction (K), and Superlative Self-Presentation (S). The F-scale raw score minus the K-scale raw score is also a common index used to detect feigned psychopathology. Numerous subscales have also been developed from the MMPI-2 test items and they are classified into three main groups: content, supplementary, and personality psychopathology.

The MMPI-2 was normed on a sample of 1138 men and 1462 women representative of the U.S. population based on 1980 census data. Internal consistency of the clinical scales varies with alpha coefficients that range from .37 (scale 6) to .86 (scale 8). Using a subset of 193 individuals from the standardization sample, test-retest (1 week) reliability for the clinical scales ranged from .61 (scale 6) to .92 (scale 0). In a review of the research literature regarding the use of the MMPI-2 in correctional settings, Megaree and Carbonell (1995) found that high scores on scales $\mathrm{F}$ and 4 , and to a lesser extent scales 8 and 9, are related to disciplinary infractions in prison and recidivism.

Additionally, the MMPI-2 now includes nine restructured clinical (RC) scales that have less item overlap and greater discriminant validity than the clinical scales (Tellegen et al., 2003). The RC scales on the MMPI-2 are identical to those on the MMPI-2-Restructured Form (MMPI-2-RF; Ben-Porath \& Tellegen, 2008), which is a recently updated and abridged version MMPI-2. One of the primary purposes of developing the RC scales was to remove the same emotional distress, unhappiness, and unpleasantness that is likely captured to some extent by 
each clinical scale. The first RC scale, Demoralization (RCd), is designed to measure this common construct. The remaining eight scales, designed to measure only one core construct with the general demoralization factor removed, are: Somatic Complaints (RC1), Low Positive Emotions (RC2), Cynicism (RC3), Antisocial Behavior (RC4), Ideas of Persecution (RC6), Dysfunctional Negative Emotions (RC7), Aberrant Experiences (RC8), and Hypomanic Activation (RC9). It should be noted that the Mf and Si scales have not been deemed to be effective in assessing core components of psychopathology (Graham, 2006), so they have no corresponding restructured scale (i.e., there is no RC5 or RC0, respectively).

Negative Treatment Indicators (TRT) is one of the 15 MMPI-2 content scales developed by Butcher, Graham, Williams, and Ben-Porath (1990). It consists of 26 items in two components: TRT1 (Low Motivation) and TRT2 (Inability to Disclose). It has been found to have an internal consistency of .79 and a test-retest reliability of .84 (mean interval $=9$ days). High scores are indicative of persons who have negative attitudes toward mental health treatment, terminate therapy prematurely, feel that no one can understand them, have problems they believe they cannot share with anyone, give up easily when problems are encountered, feel unable to make significant changes in their lives, are poor problems solvers, and often show poor judgment (Graham, 2006).

Revised Beta Examination-Third Edition (Beta III). The Beta III (Kellogg \& Morton, 1999) is the most recent version of the Revised Beta Examination which was an adaptation of the Group Beta Examination (developed by the United States Army during World War I to assess the intellectual ability of illiterate recruits) for civilian use. It is designed to be group-administered and completed in 25-30 minutes. It is validated for use with individuals aged from 16 to 89 years, including those who are non-English speakers, relatively illiterate, or have 
language difficulties. It consists of five tests (coding, picture completion, clerical checking, picture absurdities, matrix reasoning) designed to assess various facets of nonverbal intelligence including visual information processing, processing speed, spatial and nonverbal reasoning, and aspects of fluid intelligence. Sums of the five scaled scores provide an estimate of non-verbal intellectual functioning in the form of an IQ score and percentile, with results being classified similar to the Wechsler Adult Intelligence Scale-Third Edition (WAIS-III; Wechsler, 1997).

The Beta III standardization sample consisted of 1,260 adults proportioned in age, sex, race/ethnicity, education level, and geographic region of residence according to the 1990 U.S. census data. Using subsets of the standardization sample it was found the Beta III IQ scores had high test-retest reliability $(r=.91$; mean interval $=35.8$ days $)$ and a high correlation with the WAIS-III Performance and Full-Scale IQ scores ( $r=.77$ and .80 , respectively). The user manual reports that the Beta III is commonly used in prison settings and that average total scores in this population are roughly 10 points lower than in the general population (based on a sample of 388 inmates from two U.S. correctional facilities).

Wide Range Achievement Test, Third Edition (WRAT-3). The WRAT-3 (Wilkinson, 1993) is a brief measure of basic academic skills. It includes three subtests: reading recognition, spelling, and arithmetic. The reading subtest includes the recognition and naming of letters and pronunciation of words out of context. In the spelling subtest, the examinee is asked to write his or her name, and then to write letters and words as they are dictated. The arithmetic subtest involves counting, reading number symbols, solving oral problems, and doing written computations. Absolute scores, standard scores, and grade equivalent scores are provided for each subtest.

The standardization sample for the WRAT-3 included 4333 individuals aged 5 - 75 years, 
with gender, race, and education generally proportionate to the 1990 U.S. census data. With 142 individuals drawn from the standardization sample, test-retest (mean interval $=37.4$ days) reliability was found to be high at $.98, .96$, and .93 for the reading, spelling, and arithmetic subtests, respectively. With a sample of 46 children (ages 8-16) the WRAT-3 subtests showed moderate to high correlations with respective subtests on the California Test of Basic Skills $-4^{\text {th }}$ Edition (CTSB/4; CTB, 1991) at .69, .84, and .79 for reading, spelling, and arithmetic, respectively.

Tests of Adult Basic Education (TABE). The TABE (CTB/McGraw-Hill, 2004) is the most widely used assessment in adult basic and secondary education (Kirsch, Jungeblut, Jenkins, \& Kolstad, 1993). It is available in both paper-and-pencil and computer-based testing forms. Its purpose is to measure competency levels and educational progress among native English-speaking adult learners with limited literacy skills. It includes tests for reading, mathematics computation, applied mathematics, and language, as well as optional tests for vocabulary, language mechanics, and spelling tests. It is designed to be roughly comparable to material on the standard high school equivalency test (i.e., GED). Grade equivalents and percentile ranks are provided for each subtest, total mathematics, and total battery scaled scores.

The standardization sample included 1700 adults from diverse backgrounds. The technical manual for the TABE does not include a report on test/retest reliability. With a sample of 568 individuals from schools, GED testing centers, and correctional institutions who took both the TABE and the GRE within a 12-week period it was found that the TABE total battery score had a correlation of .63 with the average GED score. A recent review of relevant literature databases did not reveal any published reports of the correlation of the TABE with any version of the WRAT. 
Trail Making Test. The Trail Making Test is a brief paper-and-pencil measure that is commonly used to screen for deficits in neuropsychological functioning. The adult version consists of two parts, each composed of 25 circles that include numbers (Part A) or numbers and letters (Part B) dispersed in an irregular manner on one sheet of paper. Respondents are timed as they draw a line connecting the circles in sequence. Thus, it requires immediate recognition of the symbolic significance of numbers and letters, ability to scan the page continuously to identify the next symbol in the sequence, flexibility in integrating the numerical and alphabetical series, and completion under time pressure.

In the initial validation study of the Trail Making Test (Reitan, 1958), the time required (in seconds) to complete each part was compared between a group of 84 participants with no evidence of brain damage and 200 participants with past or present evidence of organic brain damage (as determined by a complete neurological and/or neurosurgical evaluation). Both parts were found to discriminate between groups, but Part B was particularly effective yielding a hit rate of $84.9 \%$ with a cut-score of $>91$ seconds. Based on extensive subsequent research, results are suggested to be classified into one of four categories based on the amount of time required to complete each part: perfectly normal, normal, mild/moderately impaired, and moderately/severely impaired (Reitan, 1992).

\section{Procedure}

Prior to data collection, formal approval for this study was obtained from the West Virginia Division of Corrections (WVDOC) and the Institutional Review Board (IRB) of West Virginia University. The inmates were not contacted or affected in any way in connection with this study, nor were their names or any other personally identifiable information associated with the data that were collected. The psychologist who conducts the sex offender treatment 
program at HCC maintains an updated list of all the sex offenders currently housed at the prison and designates whether they have refused, attended, or completed one or more of the three phases of treatment. This list was used to divide the participant database into three groups: those who refused treatment from the outset; those who initially accepted and attended at least one session, but later dropped-out or were expelled from treatment due to non-compliance; and those who have completed treatment or are currently enrolled in an advanced stage of treatment and have never been non-compliant with treatment.

Due to standard classification and treatment procedures designated by the WVDOC and HCC, all the variables examined in this study were available in the inmates' file. The primary sources of data were from psychological evaluations and pre-sentencing investigation reports. For the purposes of this study, these were considered the ultimate and penultimate sources of accurate information, respectively, in cases of contradictions among documents within the same inmate's file. In cases where a psychological assessment measure was administered more than once to the same inmate, the data were collected from the most recent administration. Beginning in 2008, HCC switched from administering the WRAT-3 to the TABE. Reading ability scores came from whichever one of these assessments were available. Data were also collected on all available MMPI-2 subscales, but (with the exception of the TRT scale) they are not examined in the present study.

Data were collected by this author and a fellow graduate student from 229 inmate files. The author had previous experience in conducting file review research and, as an employee at another West Virginia Division of Corrections facility, was familiar with the content and organization of the files in the present study. The graduate student assistant was trained by the author in file review procedures prior to data collection. To allow an examination of interrater 
reliability, half (25) of the files reviewed by the graduate student assistant were reviewed separately by this author. This represents $11 \%$ of the total number of files reviewed.

To minimize potential bias or systematic error, the files were numbered without treatment group designation during data collection. Treatment group designation was also deferred until the conclusion of data collection because the data was gathered on several different days over a period of three months. Therefore, it was possible that those who did not meet the criteria for study inclusion (e.g., not yet offered treatment) at the time their file was reviewed would by the end of the data collection. An updated master list of group placements was used to separate the data into the three groups previously mentioned immediately prior to conducting the statistical analyses. At the time the data was analyzed, 73 of the 229 offenders for whom files had been reviewed did not meet the criteria for study inclusion. Therefore, the final sample size for the present study was 156 .

\section{Results}

\section{Preliminary Analyses}

Reliability. Data were obtained from both raters for all variables on $25(10.9 \%)$ of the 229 files reviewed. As described in Table 1, the operational definitions of the variables collected were specific enough to require little or no judgment on the part of the rater. However, inter-rater reliability analyses were conducted to ensure the data was collected in an accurate manner. The reliability coefficients, also shown in Table 1, ranged from .83 to 1.00.

MMPI-2 validity. The MMPI-2 validity scales were examined to identify the number of participants in each group who likely produced invalid profiles due to one of three test-taking approaches: responding without consideration of item content (irrelevant responding), attempting to create an unrealistically favorable impression of themselves (defensiveness), attempting to 
create an unrealistically negative impression of themselves (feigning). The validity scale cut-off scores used in making these determinations are recommended by Graham (2006) based on his review of the empirical research (i.e., TRIN and/or VRIN T-score $\geq 80=$ irrelevant responding; $\mathrm{K}$ or L T-score $\geq 80$ and/or S T-score $\geq 70$ [and VRIN and TRIN $<80$ ] = defensiveness; and $\mathrm{F}$ T-score $\geq 80, \mathrm{Fb}$ T-score $>90, \mathrm{Fp}$ T-score $>$ 94, and/or F $-\mathrm{K}$ raw score $>10$ [and VRIN and TRIN $<80]$ = feigning) .

It was found that $9(15 \%)$ of the profiles among those who refused treatment were invalid (1 irrelevant, 3 feigning, and 5 defensiveness), 9 (15\%) of the profiles among those who were non-compliant with treatment were invalid (5 irrelevant, 3 feigning, and 1 defensiveness), and 6 $(17 \%)$ of the profiles among those who were compliant with treatment were invalid (1 irrelevant, 4 feigning, and 1 defensiveness). Because there was not a significant difference between groups, the invalid profiles were not excluded from the primary analyses. ${ }^{2}$

Diagnostic Classification. The number and types of psychiatric disorders obtained were reviewed in order to determine what comparisons could be made. WVDOC psychiatric evaluations (if completed) are included in the inmate medical files, which were not available for this study. The psychological evaluations included in WVDOC legal files and reviewed for this study do not explicitly include a diagnostic section. Names or types of disorders are often mentioned only in connection with mental health treatment history. Therefore, the presence or absence of untreated disorders is not systematically addressed. Table 2 provides a summary of the types of disorders that were cited at least once among the three treatment groups. Some participants had co-morbid disorders, in which case all diagnoses listed were included and no attempt was made to assign a primary diagnosis. None of the participants were listed as having schizophrenia or any other psychotic disorder. The two most common types of disorders were 
mood and anxiety, and these were frequently co-morbid. Because of the small sample sizes for each type of disorder, it was determined that only the absence versus presence of any psychiatric disorder would be examined in the primary analyses.

Primary Analyses

To minimize the risk of Type I error due to the large number of dependent variables in this study, a multiple analysis of variance (MANOVA) was conducted prior to examining group differences on each individual dependent variable. ${ }^{3}$ A significant effect was found for treatment group classification, Wilks 'lambda $=.013, F(2,36)=2.18, p<.05$.

Demographic Variables. Demographic information by group is provided in Table 3 for those who refused treatment, those who were non-compliant with treatment, and those who were compliant with treatment. One-way analyses of variance (ANOVAs) were conducted for the continuous variables of age and education. No significant differences were revealed. Chi-square analyses conducted for the categorical variables of race and marital status also revealed no significant differences. Because chi-square has relatively low statistical power to detect group differences, ANOVAs were also conducted on the categorical variables (coded as 0,1 , or 3 and using $\mathrm{p}<.01$ to minimize Type I error), but no group differences were revealed.

Offense Variables. Offense information for the three treatment groups is provided in Table 4. An ANOVA was conducted for the continuous variable of years to parole eligibility. A significant difference was revealed, $F(2,155)=4.87, p .<.01$, with an effect size of .69 (Cohen's d). Post-hoc analyses (Tukey HSD) indicated that those who refused treatment had more time before they were eligible for parole (5.6. years) than those who were non-compliant with treatment (3.4 years). Chi-square analyses were conducted for the categorical variables of violence during the offense, plea, offense denial, victim age (by category), victim gender, and 
relation to victim. Significant group differences were found for plea $X^{2}(2)=.83, p<.05$ and victim relation $X^{2}(6)=14.82, p<.05$. Pairwise chi-square analyses (i.e., refuse vs. non-compliant, refuse vs. compliant, and non-compliant vs. compliant) revealed that those who were non-compliant with treatment were less likely to have to have accepted a guilty plea than those who were compliant with treatment $(p<.05)$. Also, those who refused treatment were more likely to have victimized strangers than those who were compliant $(p<.05)$ or non-compliant $(p<.01)$ with treatment. No significant differences were found for the other categorical variables using chi-square analyses or ANOVAs (using numerically coded categories and $p<.01$ ).

Clinical Variables. Clinical information for the three treatment groups is provided in Table 5. Chi-square analysis revealed a significant difference for childhood sexual victimization, $X^{2}(2)=8.61, p<.05$. Pairwise chi-square analyses revealed that those who refused treatment were less likely to have reported being sexually abused as a child than those both those who were non-compliant with treatment $(p<.01)$ and those who were compliant with treatment $(\mathrm{p}<.05)$. No significant differences were found for the other clinical variables using chi-square analyses or ANOVAs (using numerically coded categories and $p<.01$ ).

Psychological Assessment Variables. Psychological assessment results for the three treatment groups is presented in Table 6. ANOVAs were conducted for IQ, reading, Trail Making Test (Part B), and MMPI-2 (validity scales, clinical scales, Restructured Clinical scales, and TRT scale) scores. Significant group differences were found for the $\operatorname{VRIN}(F(2,155)=3.98$, $p .<.05), \mathrm{L}(F(2,155)=4.87, p .<.05)$, and $\operatorname{Mf}(F(2,155)=4.87, p .<.01)$ scales of the MMPI-2. Effect sizes (Cohen's $d$ ) were $.50, .53$, and .64, respectively. Post-hoc analyses (Tukey HSD) indicated that those who refused treatment had lower VRIN and MF scores than those who 
were non-compliant with treatment and higher $\mathrm{L}$ scores than those who were compliant with treatment. No significant group differences were found for the other test scores.

Group Membership Prediction. Three logistic regression analyses were conducted to determine how well the variables identified as significant by the previous statistical analyses could predict dichotomous group membership (i.e., refuse vs. non-compliant, refuse vs. compliant, non-compliant vs. compliant).

The first regression analysis used treatment refusal versus treatment non-compliance as the dependent variable with the variables that were found to be significantly different between these groups (i.e., parole eligibility, victim relation, childhood sexual abuse, MF score, and VRIN score) as the predictor variables. The overall model was found to be significant in predicting treatment status, $X^{2}(3, n=98)=13.22, p<.01$. Three variables were retained as significant predictors: parole eligibility $(p<.01)$, VRIN score $(p<.05)$, and MF score $(p<.01)$. This revised model, presented in Table 7, correctly classified $68.8 \%$ of the participants and accounted for $20.0 \%$ and $26.7 \%$ of the variance as indicated by the Cox \& Snell R Square and Nagelkerke R Square, respectively.

Treatment refusal versus treatment compliance was the dependent variable in the second regression analysis, with the variables that were found to be significantly different between these groups (i.e., victim relation, childhood sexual abuse, and L score) as the predictor variables. The overall model was found to be significant in predicting treatment status, $X^{2}(5, \mathrm{n}=109)=28.10$, $p<.001$. Two variables were retained as significant predictors: childhood sexual abuse $(p<.05$ and $\mathrm{L}$ score $(p<.05)$. The revised model, presented in Table 8, correctly classified $66.3 \%$ of the participants and accounted for $11.0 \%$ and $15.0 \%$ of the variance as indicated by the Cox \& Snell R Square and Nagelkerke R Sqaure, respectively. 
Treatment non-compliance versus treatment compliance was the dependent variable in the final regression analysis, with the only variable that was found to be significantly different between these groups (i.e., plea) as the predictor variable. This model, presented in Table 9, was also found to be significant in predicting treatment status, $X^{2}(1, \mathrm{n}=95)=6.08, p<.05$. This model correctly classified $62.1 \%$ of the participants and accounted for $6.2 \%$ and $8.4 \%$ of the variance as indicated by the Cox \& Snell R Square and Nagelkerke R Sqaure, respectively. Secondary Analyses

The correlations (Pearson's $r$ ) between study variables (including the VRIN, L, and Mf scales of the MMPI-2) were calculated and are presented in Table 10. Although analyzing the correlations between variables was not a purpose of this study, the variables that were significantly correlated with the predictor variables $(\mathrm{p}<.01)$ are noted as they might be useful to consider in interpreting the results of the primary analyses. Plea was positively correlated with offense admission, VRIN score was negatively correlated with reading ability and victim age, and Mf score was positively correlated with reported childhood sexual victimization.

\section{Discussion}

\section{Summary of Results}

The purpose of the present study was to determine if certain demographic (age, race, marital status, education), offense-related (violent offense, plea, offense admission, victim gender, victim age, relation to victim, prior sex offense, prior felony incarceration), clinical (psychiatric diagnosis, mental health treatment, childhood sexual victimization) and psychological assessment (IQ, reading, neuropsychological, personality) factors are associated with treatment refusal, non-compliance, and compliance among incarcerated sex offenders.

There were no significant differences between these three groups on the demographic 
variables. For the offense-related variables, it was found that those who refused treatment had more time until they were eligible for parole than those who were non-compliant with treatment, and they were more likely than participants in both treatment groups to have victimized strangers. Those who were compliant with treatment were more likely to have accepted a guilty plea than those who were non-compliant with treatment. The groups differed on only one clinical variable. It was found that those who refused treatment were less likely than participants from both treatment groups to report being sexually abused when they were a child. Lastly, the only differences found on the psychological assessment scores were on the MMPI-2. It was found that those who refused treatment had lower VRIN and Mf scale scores than those who were non-compliant with treatment, and higher L scale scores than those who were compliant with treatment.

Parole eligibility date, VRIN scale score, and Mf scale score were found to be significant predictors of treatment refusal versus treatment non-compliance, whereas reported sexual abuse as a child and L scale score were significant predictors of treatment refusal versus treatment compliance. Plea was the only variable that significantly differed between the non-compliant and compliant groups and it was also found to be a significant predictor variable.

\section{Limitations}

Currently there are no published studies that have compared the characteristics of incarcerated sex offenders who refused treatment from the outset to those who accepted treatment. Thus, the present study provides a unique contribution to the literature. This places limitations, however, in comparing these results to previous studies. For all of the variables found significant in this study (with the exception of plea), the difference was found in comparison to treatment refusal from the outset, not non-compliance after initial acceptance. 
Additionally, of the seven variables that were found significant in this study, three (i.e., plea, parole eligibility, and VRIN score) have not previously been examined in connection with sex offender treatment compliance. The extent to which idiosyncratic features of the present study may have impacted these findings is difficult to determine. The treatment program associated with this study is based on techniques and principles commonly employed in other correctional facilities (e.g., cognitive-behavioral, relapse prevention), but the psychologist has flexibility in how it is implemented. No attempt was made to assess the effectiveness or acceptability of this treatment versus others. It is very possible that offender characteristics associated with treatment acceptance and compliance would differ based on type of treatment and how it is provided (e.g., male vs. female therapist). Also, the participants in the present study may not be representative of sex offenders in other settings. For example, they come from a state that is disproportionately Caucasian and rural compared to the rest of the country.

Although guided by previous empirical findings, the variables and their operational definitions included in this study were restricted due to practical reasons (i.e., information available in the inmate's file). Thus, there are many constructs with compelling empirical and/or theoretical rationale in regards to sex offender treatment compliance (e.g., victim empathy, stated motivation for treatment) which are not adequately assessed by the variables included in the present study. Unfortunately, despite the attempt made, this would also include psychiatric disorders. As noted previously, medical records (including psychiatric evaluations) were not available for review and psychologists at the correctional facility from which the sample was drawn do not systematically provide diagnoses for the inmates. Furthermore, the accuracy of the limited information that was available is questionable. Although corroborative information was typically available for all other study variables, the clinical variables (i.e., psychiatric disorder, 
mental health treatment, and childhood sexual victimization) were often based solely on self-report. Obviously, there is the possibility of the results being skewed due to the offenders possibly minimizing, exaggerating, or fabricating detail in regards to their clinical history. Given that most practitioners usually rely on self-report to a large extent, the accuracy of the information obtained in this study can be considered to be reasonably representative of what would be obtained in most clinical situations (Crassaiti \& Beech, 2004), but this limitation should be noted.

Arguably the most significant limitation of the present study is the use of dynamic criteria for classifying the participants into the three groups. For instance, some of those who are currently compliant with treatment may become non-compliant prior to treatment completion or their release from prison. This seems very likely considering that offenders designated as compliant in the present study needed only to have started Phase II treatment. Examining inmates that have already been released from prison would make compliance with a prison-based treatment program a static (non-changeable), historical factor that would increase the discriminant validity of group classification. This was not possible in the current study because only the files of offenders who were currently in prison were available for review. Also, waiting until the present participants are released before conducting the statistical analyses is not a viable option either because many of the inmates included in this study are serving very long (or even life) sentences.

\section{Directions for Future Research}

In the present study of incarcerated participants, 38\% refused treatment, 39\% accepted, but did not remain compliant with treatment, and $23 \%$ remained compliant with treatment. In comparison, Langevin (2006a), using a non-incarcerated participants, found $49 \%$ refused 
treatment, $28 \%$ started, but did not complete treatment, and $14 \%$ completed treatment. Future research should consider categorizing participants into three similar groups, as opposed to only compliant versus non-compliant, to further examine its utility and how the percentage in each group might change across settings.

Interestingly, plea was the only difference between the non-compliant and compliant groups. Willingness to accept a guilty plea could arguably be similar, but not necessarily the same as offense admission (e.g., Alford ${ }^{4}$ plea), which has been found to be associated with greater treatment compliance in studies of non-incarcerated (Craisatti \& Beech, 2004; Hunter \& Figuerdo, 1999; Langevin, 2006a; Levenson \& MacGowan, 2004) and incarcerated (Geer et al., 2001) sex offenders. However, these findings were not replicated in the present study and the correlation between plea and offense admission, although statistically significant, was not particularly high $(r=.27)$. It may be that willingness to accept a guilty plea is associated with compliance in general (e.g., conform to societal rules or expectations of others). Future treatment compliance studies using adjudicated samples should consider examining type of plea entered to help shed light on these findings.

Length of time until parole eligibility was not examined in previous research, even though its potential impact on treatment motivation was acknowledged in two of the five previous studies with incarcerated participants (Caperton et al., 2004; Geer et al., 2001) and no reasons were given in the other three studies (Kalichman et al., 1990; Moore et al., 1999; Shaw et al., 1995) as to why it may not have been a critical factor. It was found in this study that those who refuse treatment have significantly more time until parole eligibility compared to those who are non-compliant with treatment, but not compared to those more than those who are compliant with treatment. This suggests the possibility that an impending parole board hearing may provide 
sufficient motivation for some sex offenders to seek treatment, but those who begin treatment for only this reason are unable or unwilling to remain compliant with treatment. The real and/or perceived impact of treatment compliance on the duration of incarceration should be more adequately addressed in future research.

In contrast to the findings of Kalichman et al. (1990; incarcerated rapist sample) and Miner \& Dwyer (1995; non-incarcerated sample), the findings from this study could be seen as less counterintuitive and suggestive of lower, not higher, L (Lie) scale scores being associated with treatment compliance (if non-compliance is conceptualized as representing greater treatment participation than refusal). It should first of all be noted that these previous studies used the original MMPI and some of the same scales on the MMPI-2 have been slightly revised. ${ }^{5}$ However, probably more importantly, they both found the L scale was associated with subjective therapist ratings of participation level/treatment progress among treatment attendees (not examined in this study) and this study found that it was associated with treatment non-compliance compared to treatment refusal (not examined in their studies). In other words, it is unknown if similar results would have been obtained had the compliant group in this study been divided based participation level and a treatment refusal group had been included in those studies. The fact that the $\mathrm{L}$ scale did not discriminate between non-compliant and compliant participants (which would be the more appropriate comparison) in this study does seem to attenuate conclusions about its ability to predict treatment compliance among those who begin treatment. Furthermore, Geer et al. (2001) specifically examined the L scale in predicting treatment completion in a heterogeneous, incarcerated sample and found little support for its use. The present finding of the utility of the L score in predicting treatment refusal from the outset, however, should be examined in future research. 
Geer et al. (2001) found that those who completed treatment had significantly higher Pd scale scores than those who did not complete treatment. Although the present study did not find significant differences between groups on this scale, it is interesting to note that the means for all three groups $(64.4,68.0,65.5$ for refuse, non-compliant, and compliant, respectively) was near or above what considered to be clinically elevated ( $\geq 65)$. This is consistent with previous research on the MMPI-2 in correctional settings (Graham, 2006). Because individuals with scores in this range often are dishonest, selfish, manipulative, and unable to appreciate the consequences of their behavior (Megargee, 2006), it is not surprising that the findings of treatment compliance studies among outpatient samples are not always replicated among incarcerated samples.

In regards to the Mf (Masculinity-Femininity) scale, the present study and Kalichman et al. (1990) appear more consistent, but direct comparison is problematic for the same reasons listed above. The present finding suggests that those who refuse treatment are more likely than those who accept treatment (but become non-complaint) to have stereotypically masculine interests and attitudes. However, a difference was not found between those who refused treatment and those who remained compliant with treatment. Future research that uses other ways to assess the endorsement of stereotypically masculine beliefs and behaviors is warranted to determine if, and to what extent, this may impact treatment compliance.

The VRIN (Variable Response Inconsistency) scale (not included on the original MMPI) was found to significantly predict treatment refusal versus treatment non-compliance, but not treatment compliance versus the other two groups. This suggests that those who are non-compliant with treatment may also have a tendency to non-compliant with assessment and respond to test items in an inconsistent manner. More MMPI-2 profiles were deemed invalid due to irrelevant responding between the groups (5 to 1 ), but this sample size was too small to detect 
a statistically significant difference. Inconsistent responding can also be due to cognitive difficulties (Graham, 2006), and this is supported by significant correlation in the expected directions between VRIN score and reading ability $(r=-.37)$.

The present study found no significant differences between groups on the presence of a psychiatric disorder or a history of mental health treatment. Future studies that provide systematic and thorough diagnostic evaluations of mental health functioning for all study participants are needed to properly evaluate the impact of psychological problems or mental distress on treatment compliance. Surprisingly, none of the clinical or Restructured Clinical scales of the MMPI-2 discriminated between groups in the present study. This includes the Pd (Psychopathic Deviate) and RC4 (Antisocial Behavior) scales, which seems somewhat inconsistent with the findings of Langevin (2006a) and Moore et al. (1999) that psychopathy and/or Antisocial Personality Disorder adversely impact treatment compliance. However, The Psychopathy Checklist-Revised (PCL-R; Hare, 2003) was not used in this study and it is by far the most validated and accepted instrument for assessing psychopathy (Harkins \& Beech, 2007). Because it is widely used in many correctional settings, it is highly advisable and feasible for future research to examine the impact of psychopathy on sex offender treatment compliance using PCL-R scores. No significant differences were found between groups on the MMPI-2 TRT (Negative Treatment Indicators) content scale either, suggesting that previous findings that this scale is effective in identifying individuals who likely have negative attitudes towards treatment may not generalize to sex offenders.

In contrast to the findings of Geer et al. (2001), the present study did not find that those who are non-compliant with treatment are more likely to report being sexually abused as a child than those who remain compliant with treatment. Both studies used an incarcerated sample in a 
voluntary treatment program that was primarily cognitive-behavioral. Participant characteristics appear similar as well, perhaps with the exception of racial composition. Twenty-three percent of the non-compliant participants in Geer et al. were Hispanic or Native American compared to only $1 \%$ in the current study. The present study and Moore et al. (1999) are the only ones to have examined race in connection with sex offender treatment compliance. No significant differences were found, but neither study had a substantial percentage of Hispanics or Native Americans. As noted previously, the racial composition of the present study is not likely representative of sex offenders in other geographical locations. It is imperative that future research address racial and ethnic differences to facilitate interpretation and generalizability of the findings. Interestingly, the present study found that those who refuse treatment are less likely to have been sexually abused as a child than those who begin treatment (compliant or non-complaint). This is surprising considering that this has not been examined or even suggested in the literature. In fact, it is contrary to the suggestion of Geer at al. that those who have been victimized may be more likely to justify their deviant behavior and deny the need for treatment. Additionally, a significant positive correlation was found between reported childhood sexual victimization and Mf score (a significant predictor of treatment refusal). Further research in this area is clearly needed, including an examination of the factors that may impact the veracity of self-reported sexual victimization.

Victim relation was the only variable that was significantly different between groups, but did not have significant predictive ability. Considering that the two prior studies that examined victim relation in an incarcerated sample (Moore et al., 1999; Shaw et al., 1995) did not find it was associated with treatment compliance further diminishes its potential significance. Incest offenders are often considered the most benign type of sex offender and have the best prognosis 
among outpatient samples (Miner \& Dwyer, 1995), but this may not generalize to prison samples because those assigned to incarceration may disproportionately represent those who also have a history of committing other types of sexual offenses.

Although older age has been suggested by some researchers as a likely contributor to sex offender treatment acceptance and compliance because such individuals may better appreciate the consequences of deviant behavior, this has not been empirically observed in this or any other previous study. In fact, Langevin (2006a) found that non-incarcerated offenders who refuse treatment tend to be older than those who accept treatment. Shaw et al. (1995) suggest that age may not be a relevant treatment variable for incarcerated sex offenders because they are more likely to represent a subgroup of offender that is repetitive, recalcitrant, and unable to learn from experience.

Education and reading ability were not found to be significant in the present study, in contrast to the findings of Geer et al. (2001) and Shaw et al. (1995), respectively. These studies also used incarcerated samples, but, from the descriptions given, it appears that the associated treatment programs may have been more cognitively challenging (e.g., community college class component, numerous assigned readings). Therefore, it is possible that offenders who had lower education or reading ability found these programs too frustrating or difficult, which led to their becoming non-compliant or dropping-out of treatment. Potential neurological impairment (as measured by Trail Making Test - Part B scores) and IQ were not found to be significant in the present study, but they should also be considered in future studies, especially those that include a more cognitively challenging treatment program. Consistent with the findings of Kellogg and Morton (1999) in correctional settings, the mean IQ for the present sample (91.7) is roughly 10 points lower than what would likely be found in a community sample. 
Surprisingly, in contrast to all previous studies in which it was examined (Langevin, 2006a; Miner \& Dwyer, 1995; Moore et al., 1999; Shaw et al., 1995) marital status was not found to be related to treatment compliance. There are three main reasons suggested by previous researchers why incarcerated sex offenders who are married may have improved treatment compliance: (1) an increased likelihood of having a positive support system to access to help achieve and maintain gains in treatment, (2) having a partner to return to after treatment may provided increased motivation to change, and (3) it may be indicative of greater interpersonal skills and empathy that are useful or necessary for a successful treatment outcome (Shaw et al., 1995). Obviously, all three of these reasons may also apply to individuals who are in committed relationships, but not legally married. Future research that includes a broader construct (e.g., relationship status) may more useful in finding evidence to support one or more of the above-mentioned suggestions.

A common division of sex offender subtypes in the literature is rapist versus child molester. This study did not employ those terms, but it did examine victim age, and the operational definition of a rapist in most studies is an offender who has committed a sexual assault involving physical contact (as opposed to non-contact offenses such as exhibitionism or voyeurism) of a victim age 18 or older. None of the participants in the present study were convicted solely of a non-contact offense ${ }^{6}$ and the percentage of offenders in each of the three groups in the present study who had adult victims did not significantly differ. Shaw et al. (1995) also found no effect for victim age in an incarcerated sample. However, it is may be more useful for future research to consider prepubescent versus postpubescent categorization of victims, rather than statutorily-defined adult versus child, because Moore et al. (1999) did find that incarcerated sex offenders who had victims 13 years of age or older were less likely to be 
compliant with treatment than those who had victims 12 years of age or younger. Although having male victims has been found to be associated with increased recidivism (Hanson, 2000), it does not appear to be associated with treatment compliance based on the findings of the present study as well as the two previous studies in which it was examined (Craissati \& McClurg, 1997; Moore et al., 1999).

Craissati and McClurg (1997) found that violence during the offense was associated with treatment non-compliance among non-incarcerated offenders, but the non-significant results of the present study are consistent with the only previous study that examined this variable among incarcerated offenders (Moore et al., 1999), despite differences in base rates (64\% vs. 16\%, respectively). Prior sex offenses and felony incarcerations were examined because extensive criminal history may be related to impulsivity and self-control issues (Hanson \& Morton-Bourgon, 2005). Offenders with increased impulsivity and lower self-control may have a difficult time completing a treatment program that requires commitment and responsibility (Geer et al., 2001). As expected, there was a significant correlation between these two variables $(r=.36)$, but they may be useful to consider separately because sex offenses do not invariably lead to felony convictions and incarceration, and most of the previous incarcerations noted in this study were for non-sexual crimes. Although the present study did not find these variables to be associated with treatment compliance, future research is encouraged because of their significance in previous treatment compliance studies (Miner \& Dwyer, 1995; Crassati \& McClurg, 1997; Geer et al., 2001; Langevin, 2006a) and future recidivism (Hanson, 2000), the primary indicator of the effectiveness of a sex offender treatment program.

As previously mentioned, classifying the participants into refusal, non-compliant, and compliant groups prior to their release from prison is a significant limitation of this study and 
precludes any strong conclusions being drawn from the results. It may be useful to revisit these data after several years utilizing updated information regarding their compliance with treatment. In fact, it is planned that once an appropriate follow-up period has passed the present data will be used in future research that will examine recidivism and its relation to treatment compliance. Identifying the factors that are associated with treatment non-compliance has several potential treatment implications. For example, the negative impact of certain factors may be minimized if they are addressed prior to treatment for sexual deviance issues and other factors might be better dealt with by modifying existing treatment programs. Understanding which factors are more intractable obstacles to treatment success can be useful in risk assessment and the allocation of limited treatment resources. 


\section{References}

Abel, G. G., \& Becker, J. V. (1985). Sexual Interest Cardsort. Atlanta: Behavioral Medicine Laboratory, Emory University.

Abel, G. G., Becker, J. V., \& Cunningham-Rathner, J. (1984). Complications, consent, and cognitions in sex between children and adults. International Journal of Law and Psychiatry, 7, 89-103.

American Psychiatric Association (2000). Diagnostic and statistical manual of mental disorders ( $4^{\text {th }}$ ed., text revision). Washington, DC: Author.

Anderson, R. Gibeau, D., \& D’ Amora, D.A. (1995). The sex offender treatment rating scale: Initial reliability data. Sexual Abuse: A Journal of Research and Treatment, 7, 221-228.

ATSA. (2001). Practice standards and guidelines for memebers of the Association for the Treatment of Sexual Abusers. Beaverton, OR: Author.

Aytes, K. E., Olsen, S. S., Zakrajsek, T., Murray, P., \& Ireson, R. (2001). Cognitive/behavioral treatment for sexual offenders: An examination of recidivism. Sexual Abuse: A Journal of Research and Treatment, 13, 223-231.

Barnes, A. R., Baca, M., Dix, M., Flahr, S., Gaal, C., Whitaker, M., et al. (1994). Sex offender treatment project: Literature review. Retrieved April 22, 2008, from http://reviewjustice. ua.a.alaska.edu/research/1990/9419litreview.pdf

Ben-Porath, Y. S., \& Tellegen, A. (2008). MMPI-2-RF: Manual for administration, scoring, and interpretation. Mineapolis: University of Minnesota Press.

Bureau of Justice Statistics (2007). Criminal offenders statistics. Retrieved July 8, 2008, from http://ojp.usdoj.gov/bjs/crimoff.htm\#sex

Buss, A. H., \& Durkee, A. (1957). An inventory for assessing different kinds of hostility. 
Journal of Consulting Psychology, 21, 343-349.

Butcher, J. N., Graham, J. R., Williams, C. L., \& Ben-Porath, Y. S. (1990). Development and use of the MMPI-2 content scales. Minneapolis: University of Minnesota Press.

Butcher, J. N., Williams, C. L., Graham, J. R., Tellegen, A., \& Kaemer, B. (1989). MMPI-2: Manual for administration and scoring. Minneapolis: University of Minnesota Press.

Caperton, J. D., Edens, J. F., \& Johnson, J. K. (2004). Predicting sex offender institutional adjustment and treatment compliance using the Personality Assessment Inventory. Psychological Assessment, 16, 187-191.

Collaborative Outcome Data Committee (2007). Sexual offender treatment outcome research: Guidelines for evaluation. Retrieved April 22, 2008, from http://www.ps-sp.gc.ca/res/ cor/rep/_fl/CODC_07_e.pdf

Craig, L. A., Browne, K. D., \& Stringer, I. (2003). Treatment of sexual offence recidivism. Trauma, Violence, and Abuse, 4, 70-89.

Craissati, J., \& Beech, A. (2004). The characteristics of a geographical sample of convicted rapists: Sexual victimization and compliance in comparison to child molesters. Journal of Interpersonal Violence, 19, 371-388.

Craissati, J., \& McClurg, G. (1997). The Challenge Project: A treatment program evaluation for perpetrators of child sexual abuse. Child Abuse and Neglect, 21, 637-648.

CTB. (1991). CTBS/4 technical report. Monterey, CA: Macmillan/McGraw-Hill.

CTB/McGraw-Hill. (2004). TABE technical report: Form 9 and 10 (all levels). Monterey, CA: Author.

Doren, D. M. (1998). Recidivism base rates, predictions of sex offender recidivism, and the sexual predator commitment laws. Behavioral Sciences and the Law, 16, 97-114. 
Geer. T. M., Becker, J. V., Gray, S. R., \& Krauss, D. (2001). Predictors of treatment completion in a correctional sex offender treatment program. International Journal of Offender Therapy and Comparative Criminology, 45, 302-313.

Graham, J. R. (2006). MMPI-2: Assessing Personality and Psychopathology (4 ${ }^{\text {th }}$ Ed.). New York: Oxford University Press.

Hall, G. C., \& Nagayama, C. (1995). Sexual offender recidivism revisited: A meta-analysis of recent treatment studies. Journal of Consulting and Clinical Psychology, 63, 802-809.

Hanson, R. K. (2000). Will they do it again? Predicting sex-offense recidivism. Current Directions in Psychological Science, 9, 106-109.

Hanson, R. K., \& Morton-Bourgon, K. E. (2005). The characteristics of persistent sexual offenders: A meta-analysis of recidivism studies. Journal of Consulting and Clinical Psychology, 73, 1154-1163.

Hare, R. D. (2003). The Hare Psychopathy Checklist-Revised (PCL-R), $2^{\text {nd }}$ Ed. Toronto, Canada: Multi-Health Systems.

Harkins, L., \& Beech, A. R. (2007). A review of the factors that can influence the effectiveness of sexual offender treatment: Risk, need responsivity, and process issues, 12, 615-627.

Hathaway, S. R., \& McKinley, J. C. (1940). A multiphasic personality schedule (Minnesota): I. Construction of the schedule. Journal of Psychology, 10, 249-254.

Hunter, J. A., \& Figueredo, A. J. (1999). Factors associated with treatment compliance in a population of juvenile sexual offenders. Sexual Abuse: A Journal of Research and Treatment, 11, 49-67.

Jastak, S., \& Wilkinson, G. S. (1984). Wide Range Achievement Test-Revised. Wilmington, DE: Jastak Associates. 
Kalichman, S. C., Shealy, L., \& Craig, M. E. (1990). The use of the MMPI in predicting treatment participation among incarcerated adult rapists. Journal of Psychology and Human Sexuality, 3, 105-119.

Kellogg, C. E., \& Morton, N. W. (1999). Beta III manual. San Antonio, TX: Psychological Corporation.

Kirsch, I. S., Jungeblut, A., Jenkins, L., \& Kolstad, A. (1993). Adult Literacy in America: A First Look at the Results of the National Adult Literacy Survey. Washington D.C.: U.S. Department of Education.

Lalumiere, M. L., Quinsey, V. L., Harris, G. T., Rice, M. E., \& Trautrimas, C. (2003). Are rapists differentially aroused by coercive sex in phallometric assessments? Annals of the New York Academy of Sciences, 989, 211-224.

Langevin, R. (2006a). Acceptance and completion of treatment among sex offenders. International Journal of Offender Therapy and Comparative Criminology, 50, 402-417.

Langevin, R. (2006b). Sexual offenses and traumatic brain injury. Brain and Cognition, 60, 206-207.

Leary, M. R. (1983). A brief version of the Fear of Negative Evaluation Scale. Personality and Social Psychology Bulletin, 9, 371-376

Levenson, J. S., \& Macgowan, M. J. (2004). Engagement, denial, and treatment progress among sex offenders in group therapy. Sexual Abuse: A Journal of Research and Treatment, 16, 49-63.

Losel, F., \& Schmucker, M. (2005). The effectiveness of treatment for sexual offenders: A comprehensive meta-analysis. Journal of Experimental Criminology, 1, 117-146.

Macgowan, M. J. (2000). Evaluation of a measure of engagement for group work. Research on 
Social Work Practice, 10, 348-361.

Maletzky, B. M., \& Steinhauser, C. (2002). A 25-year follow up of cognitive/behavioral therapy with 7,275 sexual offenders. Behavior Modification, 26, 123-147.

Marques, J. K., Day, D. M., Nelson, C., \& West, M. A. (1994). The assessment and treatment of sex offenders. Criminal Justice and Behavior, 21, 28-54.

Megargee, E. L. (2006). Using the MMPI-2 in Criminal Justice and Correctional Settings Assessing Personality and Psychopathology ( $4^{\text {th }}$ Ed.). Minneapolis, MN: University of Minnesota Press.

Megargee, E. L., \& Carbonell, J. L. (1995). Use of the MMPI-2 in correctional settings. In Y. S. Ben-Porath, J. R. Graham, G. C. N. Hall, R. D. Hirshman, \& M. S. Zaragoza (Eds.), Forensic Applications of the MMPI-2 (pp. 127-159). Thousand Oaks, CA: Sage.

Miner, M. H., \& Dwyer, S. M. (1995). Analysis of dropouts from outpatient sex offender treatment. Journal of Psychology and Human Sexuality, 7, 77-93.

Moore, D. L., Bergman, B. A., \& Knox, P. L. (1999). Predictors of sex offender treatment completion. Journal of Child Sexual Abuse, 7, 73-88.

Morey, L. C. (1996). Personality Assessment Inventory manual. Odessa, FL: Psychological Assessment Resources.

Nichols, H. R., \& Molinder, I. (1984). Multiphasic sexual inventory manual. Tacoma, WA: Nichols \& Molinder Associates.

Nichols, H. R., \& Molinder, I. (1996). Multiphasic sexual inventory II handbook. Tacoma, WA: Nichols \& Molinder Associates

North Carolina v. Alford, 400 U.S. 25 (1970).

Pithers, W. D., Marques, J. K., Gibat, C. C., \& Marlatt, G. A. (1983). Relapse prevention with 
sexual aggressives: A self-control model of treatment and maintenance of change. In J. G. Greer \& I. R. Stuart (Eds.), The sexual aggressor: Current perspectives on treatment (pp. 214-239). New York: Van Nostrand Reinhold.

Polaschek, D. L. L. (2003) Relapse prevention, offense process models, and the treatment of sexual offenders. Professional Psychology: Research and Practice, 34, 361-367.

Reitan, R. M. (1958). The validity of the Trail Making Test as an indicator of organic brain damage. Perceptual and Motor Skills, 8, 271-276.

Reitan, R. M. (1992). Trail Making Test: Manual for administration and scoring. Tucson, AZ: Neuropsychology Press.

Rice, M. E., \& Harris, G. T. (2003). The size and sign of treatment effects in sex offender therapy. Annals of the New York Academy of the Sciences, 989, 428-440.

Robertiello, G., \& Terry, K. J. (2007). Can we profile sex offenders? A review of sex offender typologies. Aggression and Violent Behavior, 12, 508-518.

Roid, G. H., \& Fitts, W. H. (1991). Tennessee self concept scale manual. Los Angeles, CA: Western Psychological Services.

Schneider, S. L., \& Wright, R. C. (2001). The FoSOD: A measurement tool for reconceptualizing the role of denial in child molesters. Journal of Interpersonal Violence, $16,545-564$.

Seto, M. C., \& Kuban, M. (1996). Criterion-related validity of a phallometric test for paraphilic rape and sadism. Behaviour Research and Therapy, 34, 175-183.

Shaw, T. A., Herkov, M. J., \& Greer, R. A. (1995). Examination of treatment completion and predicted outcome among incarcerated sex offenders. Bulletin of the American Academy of Psychiatry and Law, 23, 35-41. 
Spence, J. T., Helmreich, R., \& Stapp, J. (1973). A short version of the Attitudes toward Women Scale (AWS). Bulletin of the Psychonomic Society, 2, 219-220.

Tellegen, A., Ben-Porath, Y. S., Sellbon, M., Arbisi, P. A., McNulty, J. L., \& Graham, J. P. (2003). MMPI-2 Restructured Clinical (RC) Scales: Development, validation, and interpretation. Minneapolis: University of Minnesota Press.

Wilkinson, G. S. (1993). Wide Range Achievement Test-Revision 3. Wilmington, DE: Jastak Association.

Wechsler, D. (1981). Wechsler Adult Intelligence Scale-Revised manual. San Antonio, TX: The Psychological Corporation.

Wechsler, D. (1997). WAIS-III administration and scoring manual. San Antonio, TX: The Psychological Corporation. 


\section{Appendix}

§61-8B-1. Sexual offenses.

In this article, unless a different meaning plainly is required: (1) "Forcible compulsion" means: (a) Physical force that overcomes such earnest resistance as might reasonably be expected under the circumstances; or (b) Threat or intimidation, expressed or implied, placing a person in fear of immediate death or bodily injury to himself or herself or another person or in fear that he or she or another person will be kidnapped; or (c) Fear by a person under sixteen years of age caused by intimidation, expressed or implied, by another person who is at least four years older than the victim. For the purposes of this definition "resistance" includes physical resistance or any clear communication of the victim's lack of consent. (2) "Married", for the purposes of this article in addition to its legal meaning, includes persons living together as husband and wife regardless of the legal status of their relationship. (3) "Mentally defective" means that a person suffers from a mental disease or defect which renders that person incapable of appraising the nature of his or her conduct. (4) "Mentally incapacitated" means that a person is rendered temporarily incapable of appraising or controlling his or her conduct as a result of the influence of a controlled or intoxicating substance administered to that person without his or her consent or as a result of any other act committed upon that person without his or her consent. (5) "Physically helpless" means that a person is unconscious or for any reason is physically unable to communicate unwillingness to an act. (6) "Sexual contact" means any intentional touching, either directly or through clothing, of the breasts, buttocks, anus or any part of the sex organs of another person, or intentional touching of any part of another person's body by the actor's sex organs, where the victim is not married to the actor and the touching is done for the purpose of gratifying the sexual desire of either party. (7) "Sexual intercourse" means any act between persons involving 
penetration, however slight, of the female sex organ by the male sex organ or involving contact between the sex organs of one person and the mouth or anus of another person.(8) "Sexual intrusion" means any act between persons involving penetration, however slight, of the female sex organ or of the anus of any person by an object for the purpose of degrading or humiliating the person so penetrated or for gratifying the sexual desire of either party. (9) "Bodily injury" means substantial physical pain, illness or any impairment of physical condition. (10) "Serious bodily injury" means bodily injury which creates a substantial risk of death, which causes serious or prolonged disfigurement, prolonged impairment of health or prolonged loss or impairment of the function of any bodily organ. (11) "Deadly weapon" means any instrument, device or thing capable of inflicting death or serious bodily injury, and designed or specially adapted for use as a weapon, or possessed, carried or used as a weapon. (12) "Forensic medical examination" means an examination provided to a possible victim of a violation of the provisions of this article by medical personnel qualified to gather evidence of the violation in a manner suitable for use in a court of law, to include: An examination for physical trauma; a determination of penetration or force; a patient interview; and the collection and evaluation of other evidence that is potentially relevant to the determination that a violation of the provisions of this article occurred and to the determination of the identity of the assailant.

$\S 61-8 \mathrm{~B}-2$. Lack of consent.

(a) Whether or not specifically stated, it is an element of every offense defined in this article that the sexual act was committed without the consent of the victim. (b) Lack of consent results from: (1) Forcible compulsion; or (2) Incapacity to consent; or (3) If the offense charged is sexual abuse, any circumstances in addition to the forcible compulsion or incapacity to consent in which the victim does not expressly or impliedly acquiesce in the actor's conduct. (c) A person is 
deemed incapable of consent when such person is: (1) Less than sixteen years old; or (2)

Mentally defective; or (3) Mentally incapacitated; or (4) Physically helpless.

$\S 61-8 \mathrm{~B}-3$. Sexual assault in the first degree.

(a) A person is guilty of sexual assault in the first degree when: (1) The person engages in sexual intercourse or sexual intrusion with another person and, in so doing: (i) Inflicts serious bodily injury upon anyone; or (ii) Employs a deadly weapon in the commission of the act; or (2) The person, being fourteen years old or more, engages in sexual intercourse or sexual intrusion with another person who is younger than twelve years old and is not married to that person.

$\S 61-8-12$. Incest;

(a) For the purposes of this section: (1) "Aunt" means the sister of a person's mother or father;

(2) "Brother" means the son of a person's mother or father; (3) "Daughter" means a person's natural daughter, adoptive daughter or the daughter of a person's husband or wife; (4) "Father" means a person's natural father, adoptive father or the husband of a person's mother; (5)

"Granddaughter" means the daughter of a person's son or daughter; (6) "Grandfather" means the father of a person's father or mother; (7) "Grandmother" means the mother of a person's father or mother; (8) "Grandson" means the son of a person's son or daughter; (9) "Mother" means a person's natural mother, adoptive mother or the wife of a person's father; (10) "Niece" means the daughter of a person's brother or sister; (11) "Nephew" means the son of a person's brother or sister; (12) "Sexual intercourse" means any act between persons involving penetration, however slight, of the female sex organ by the male sex organ or involving contact between the sex organs of one person and the mouth or anus of another person; (13) "Sexual intrusion" means any act between persons involving penetration, however slight, of the female sex organ or of the anus of any person by an object for the purpose of degrading or humiliating the person so penetrated or 
for gratifying the sexual desire of either party; (14) "Sister" means the daughter of a person's father or mother; (15) "Son" means a person's natural son, adoptive son or the son of a person's husband or wife; and (16) "Uncle" means the brother of a person's father or mother.

(b) A person is guilty of incest when such person engages in sexual intercourse or sexual intrusion with his or her father, mother, brother, sister, daughter, son, grandfather, grandmother, grandson, granddaughter, nephew, niece, uncle or aunt. 


\section{Footnotes}

${ }^{1}$ Despite its popularity, there are noted limitations and criticisms of the relapse prevention approach to sex offender treatment (Polaschek, 2003).

${ }^{2}$ Analyses were also conducted with the invalid MMPI-2 profiles excluded and there were no significant changes in the findings.

${ }^{3}$ This included the 36 continuous variables of age, education, parole eligibility date, and scores for the Beta III, WRAT-3/TABE, Trails B, and MMPI-2 scales.

3"An individual accused of crime may voluntarily, knowingly, and understandingly consent to the imposition of a prison sentence even if he is unwilling or unable to admit his participation in the acts constituting the crime, when he intelligently concludes that his interests require entry of a guilty plea and the record before the judge contains strong evidence of actual guilt" (Supreme Court ruling in North Carolina v. Alford, 1970).

${ }^{5}$ Some items were deleted or changed for the purpose of eliminating possibly sexist wording, simplification, modernization of idioms, or grammatical clarification (Graham, 2006).

${ }^{5}$ This is probably due to non-contact offenders typically receiving legal impositions less than imprisonment (e.g., probation, fines, time served in jail) and is not necessarily an indication of the infrequency of non-contact sexual offenses. 
Table 1

Definitions of the Study Variables and Interrater Agreement

Variable

Definition

Kappa (or ICC)

Age

Current age in years

Education

Highest level of education obtained in years, not including GED

Marital Status

Current status of: never married, divorced/separated/widowed, or 1.00 married

Race

Caucasian, African-American, Hispanic, Asian, or other

Violent Offense

yes or no, charged with or met the criteria for $1^{\text {st }}$ Degree Sexual

.855 Assault (see Appendix), or a crime that involved the use of a deadly weapon and/or serious physical injury to the victim (e.g., murder, malicious wounding)

Plea

Guilty/plea-bargained or not guilty/found guilty by jury

Crime Admission yes or no, admitted to any illicit sexual behavior in connection with his current sexual conviction

Parole Eligibility length of time in years from the time of data analysis

Victim Gender male, female, or both

Victim Relation

stranger $=$ no contact with an unrelated victim prior to the offense. acquaintance $=$ some contact with an unrelated victim prior to the offense. relative $=$ as legally defined for incest $(\mathrm{see}$ Appendix)

Victim Age

average age at time of offense(s) $=$ under $13,13-17$, over 17 , or more than one age group

Psychiatric Disorder the name or type of all Axis I or II disorders for which the inmate has been diagnosed

Mental Health yes or no, any formal mental health treatment history

Treatment 
(Table 1 continued)

Prior Sex Offense yes or no, any previous conviction for a sexual offense

Prior Incarceration yes or no, any prior incarceration for a felony conviction

Sexual Abuse

yes or no, offender reports he was the victim of victim of sexual abuse as a child

IQ Score

Total score on the most recent administration of the Beta III

Reading Ability

Grade level in years and months on the most recent

Neurological administration of the WRAT-3 or TABE

Deficits

Time to complete (in seconds) on the most recent

Personality administration of Trail Making Test Part B

Assessment

T-scores on the most recent administration of the MMPI-2 validity, clinical, restructured clinical, and TRT scales; and

F-scale raw score minus K-scale raw score

*For all scales 
Table 2

Types of Psychiatric Disorders by Group

\begin{tabular}{lccc} 
& \multicolumn{3}{c}{ Group } \\
\cline { 2 - 4 } & Refused & Non-Compliant & Compliant \\
& $(n=61)$ & $(n=59)$ & $(n=36)$ \\
& $n(\%)$ & $n(\%)$ & $n(\%)$ \\
Disorder & $34(55.7)$ & $29(49.2)$ & $25(69.4)$ \\
\hline None listed & $14(23.0)$ & $5(8.5)$ & $9(25.0)$ \\
Mood & $5(8.2)$ & $10(16.9)$ & $1(2.7)$ \\
Anxiety & $2(3.3)$ & $1(1.7)$ & $1(2.7)$ \\
Attention-Deficit/Disruptive Behavior & $1(1.6)$ & $2(3.4)$ & $0(0.0)$ \\
Pervasive Developmental & $2(3.3)$ & $4(6.8)$ & $1(2.7)$ \\
Substance-Related & $1(1.6)$ & $2(3.4)$ & $1(2.7)$ \\
Sleep & $1(1.6)$ & $1(1.7)$ & $0(0.0)$ \\
Sexual and Gender Identity & $1(1.6)$ & $2(3.4)$ & $0(0.0)$ \\
Impulse Control & $4(6.8)$ & $1(2.7)$ \\
Personality & $1(1.6)$ & & \\
\hline
\end{tabular}

Note. Total group percentages exceed $100 \%$ due to co-morbidity. 
Table 3

Demographic Variables by Group

\section{Group}

\begin{tabular}{|c|c|c|c|c|c|}
\hline & $\begin{array}{l}\text { Refused } \\
(n=61)\end{array}$ & $\begin{array}{l}\text { Non-Compliant } \\
\qquad(n=59)\end{array}$ & $\begin{array}{l}\text { Compliant } \\
(n=36)\end{array}$ & & \\
\hline Continuous Variables & $M(S D)$ & $M(S D)$ & $M(S D)$ & $F(2,155)$ & $p$ \\
\hline Age & $40.8(11.0)$ & $40.8(12.4)$ & $41.3(13.7)$ & 0.02 & $n s$ \\
\hline Education & $10.0(2.1)$ & $9.9(2.3)$ & $10.8(2.3)$ & 1.73 & $n s$ \\
\hline Categorical Variables & $n(\%)$ & $n(\%)$ & $n(\%)$ & $X^{2}(\mathrm{df})$ & $p$ \\
\hline Marital Status & & & & $3.76(4)$ & $n s$ \\
\hline Never Married & $25(41)$ & $16(27.1)$ & $14(38.9)$ & & \\
\hline Married & $12(19.7)$ & $16(27.1)$ & $6(16.7)$ & & \\
\hline Divorced/Other & $24(39.3)$ & $27(45.8)$ & $16(44.4)$ & & \\
\hline Race & & & & $2.12(4)$ & $n s$ \\
\hline Caucasian & $53(86.9)$ & $52(88.1)$ & $29(80.6)$ & & \\
\hline African-American & $8(13.1)$ & $6(10.2)$ & $5(13.9)$ & & \\
\hline Other & $0(0.0)$ & $1(1.7)$ & $2(5.6)$ & & \\
\hline
\end{tabular}


Table 4

Offense Variables by Group

Group

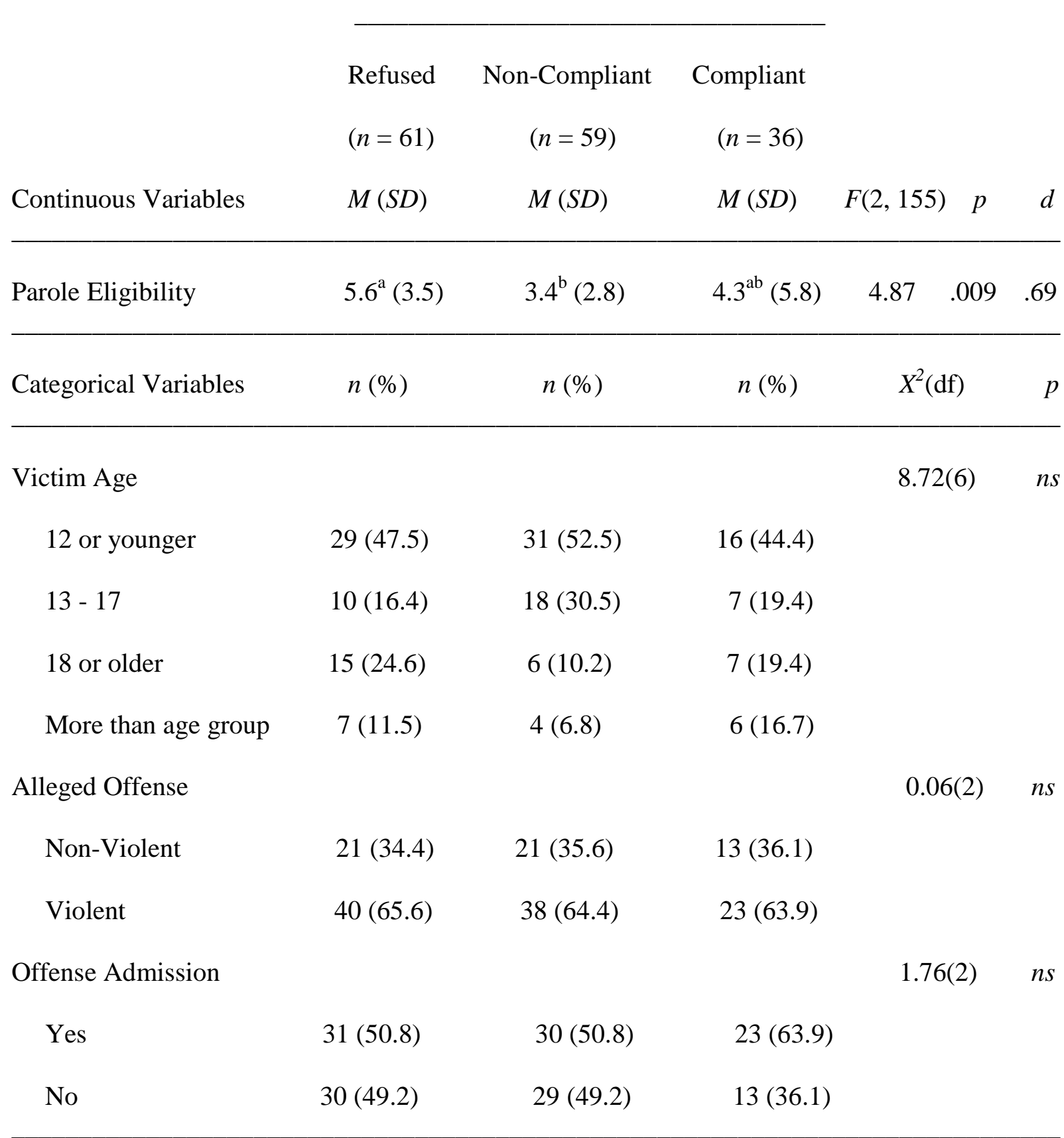

(Table 4 continues) 
(Table 4 continued)

Plea

6.83(2) .033

Guilty

$54(88.5)$

45 (76.3)

34 (94.4)

Not Guilty

$7(11.5)^{\mathrm{ab}}$

$14(23.7)^{\mathrm{a}}$

$2(5.6)^{\mathrm{b}}$

Victim Gender

1.64(4) ns

Female

$53(86.9)$

$51(86.4)$

$30(83.3)$

Male

7 (11.5)

$5(8.5)$

$4(11.1)$

Both

1 (1.6)

$3(5.1)$

$2(5.6)$

Victim Relation

14.82(6) .022

Stranger

$11(18.0)^{\mathrm{a}}$

$2(3.4)^{b}$

$2(5.6)^{b}$

Acquaintance

$24(39.4)$

$32(54.2)$

$17(47.2)$

Relative

$26(42.6)$

$22(37.3)$

$14(38.9)$

More then one relation

$0(0.0)$

$3(5.1)$

$3(8.3)$

Prior Sex Offense

1.24(2) $n s$

Yes

7 (11.5)

$9(15.3)$

7 (19.4)

No

$54(88.5)$

$50(84.7)$

$21(58.3)$

Prior Incarceration

Yes

$31(50.8)$

$30(50.8)$

15 (41.7)

No

$30(49.2)$

$29(49.2)$

$21(58.3)$

Note. $d=$ effect size. Means in the same row that do not share superscripts are significantly different in the Tukey honestly significant difference comparison. Percentages in the same row that do not share superscripts are significantly different in pairwise comparisons. 
Table 5

Clinical Variables by Group

Group

\begin{tabular}{|c|c|c|c|c|c|}
\hline & $\begin{array}{l}\text { Refused } \\
\qquad(n=61)\end{array}$ & $\begin{array}{c}\text { Non-Compliant } \\
\qquad(n=59)\end{array}$ & $\begin{array}{l}\text { Compliant } \\
\qquad(n=36)\end{array}$ & & \\
\hline Variable & $n(\%)$ & $n(\%)$ & $n(\%)$ & $X^{2}(\mathrm{df})$ & $p$ \\
\hline Psychiatric Diagnosis & & & & $3.75(2)$ & $n s$ \\
\hline Yes & $27(44.3)$ & $30(50.8)$ & $11(30.6)$ & & \\
\hline No & $34(55.7)$ & $29(49.2)$ & $25(69.4)$ & & \\
\hline
\end{tabular}

Mental Health Treatment

3.65(2) ns

$\begin{array}{llll}\text { Yes } & 23(37.7) & 21(35.6) & 7(19.4) \\ \text { No } & 38(62.3) & 38(64.4) & 29(80.6)\end{array}$

Sexually Abused as a Child

8.61(2) $\quad .014$

$\begin{array}{lrrr}\text { Yes } & 7(11.5)^{\mathrm{a}} & 19(32.2)^{\mathrm{b}} & 11(30.6)^{\mathrm{b}} \\ \text { No } & 54(88.5) & 40(67.8) & 25(69.4)\end{array}$

Percentages in the same row that do not share superscripts are significantly different in pairwise comparisons. 
Table 6

Psychological Assessment Scores by Group

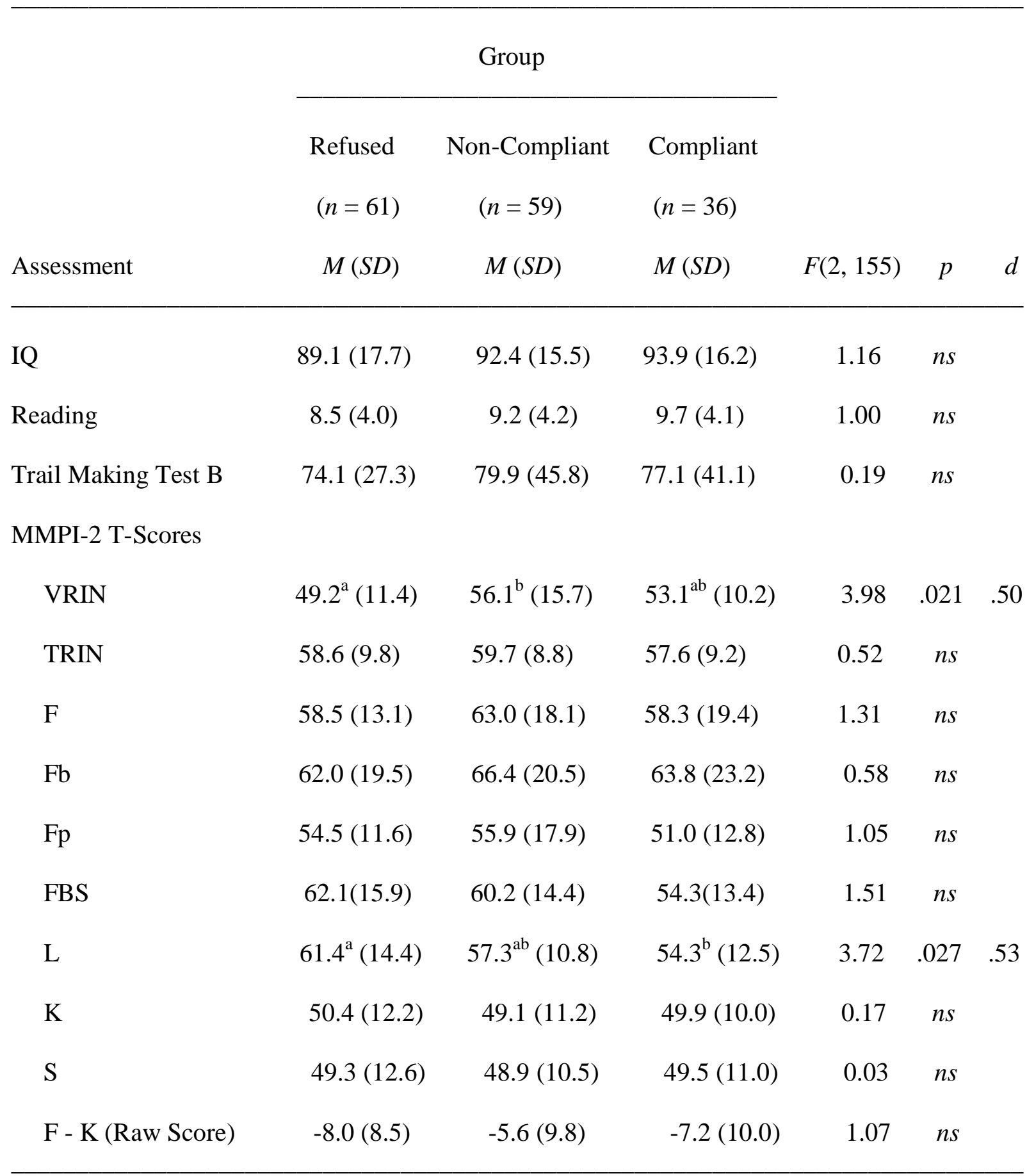

(Table 6 continues) 
(Table 6 continued)

\begin{tabular}{|c|c|c|c|c|c|}
\hline Hs & $59.2(13.1)$ & $64.1(15.6)$ & $58.0(14.0)$ & 2.64 & $n s$ \\
\hline $\mathrm{D}$ & $59.9(13.3)$ & $63.4(12.8)$ & $58.9(12.0)$ & 1.66 & $n s$ \\
\hline Hy & $55.3(15.2)$ & $58.5(15.2)$ & $55.4(14.8)$ & 0.82 & $n s$ \\
\hline $\mathrm{Pd}$ & $64.4(11.9)$ & $68.0(11.6)$ & $65.5(12.7)$ & 1.37 & $n s$ \\
\hline Mf & $41.0^{\mathrm{a}}(8.6)$ & $46.6^{\mathrm{b}}(8.9)$ & $44.8^{\mathrm{ab}}(8.0)$ & 6.39 & .002 \\
\hline $\mathrm{Pa}$ & $58.7(14.1)$ & $65.3(15.8)$ & $62.9(15.7)$ & 2.91 & $n s$ \\
\hline $\mathrm{Pt}$ & $57.4(14.0)$ & $63.2(14.7)$ & $58.3(13.4)$ & 2.70 & $n s$ \\
\hline $\mathrm{Sc}$ & $59.1(13.4)$ & $65.2(16.0)$ & $59.9(18.0)$ & 0.09 & $n s$ \\
\hline Ma & $53.4(9.6)$ & $54.6(11.1)$ & $53.2(11.8)$ & 0.78 & $n s$ \\
\hline $\mathrm{Si}$ & $54.6(13.3)$ & $58.3(12.8)$ & $54.8(11.7)$ & 1.43 & $n s$ \\
\hline $\mathrm{RCd}$ & $54.7(14.2)$ & $57.7(13.3)$ & $54.2(13.0)$ & 0.78 & $n s$ \\
\hline $\mathrm{RC} 1$ & $58.2(14.6)$ & $62.7(16.3)$ & $59.1(17.1)$ & 1.04 & $n s$ \\
\hline $\mathrm{RC} 2$ & $51.5(12.6)$ & $53.8(11.5)$ & $48.9(8.8)$ & 1.65 & $n s$ \\
\hline $\mathrm{RC} 3$ & $57.0(12.0)$ & $53.7(11.1)$ & $55.3(11.8)$ & 0.97 & $n s$ \\
\hline $\mathrm{RC} 4$ & $61.4(13.6)$ & $62.2(12.6)$ & $59.6(10.8)$ & 0.42 & $n s$ \\
\hline RC6 & $59.7(11.0)$ & $60.4(12.8)$ & $59.9(14.4)$ & 0.91 & $n s$ \\
\hline $\mathrm{RC} 7$ & $52.0(15.3)$ & $57.0(15.1)$ & $53.3(12.6)$ & 1.48 & $n s$ \\
\hline $\mathrm{RC} 8$ & $53.1(12.4)$ & $55.4(11.8)$ & $53.0(11.9)$ & 0.57 & $n s$ \\
\hline RC9 & $47.0(12.8)$ & $46.5(8.4)$ & $47.5(9.7)$ & 0.09 & $n s$ \\
\hline
\end{tabular}

(Table 6 continues) 
(Table 6 continued)

\begin{tabular}{llllll}
\hline TRT & $55.6(13.9)$ & $60.3(13.3)$ & $55.8(14.9)$ & 1.80 & $n s$ \\
\hline
\end{tabular}

Note. $d=$ effect size. Means in the same row that do not share superscripts are significantly different in the Tukey honestly significant difference comparison. 
Table 7

Logistic Regression Prediction of Treatment Refusal Versus Treatment Non-Compliance

95\% Confidence Intervals

Predictor $\quad B \quad$ S.E. Wald $\quad p \quad$ Odds Ratio Lower Limit Upper Limit

\begin{tabular}{lccccccc}
\hline Parole Date & -.204 & .074 & 7.514 & .006 & .815 & .705 & .944 \\
VRIN & .040 & .018 & 4.717 & .030 & 1.041 & 1.004 & 1.079 \\
Mf & .070 & .025 & 7.722 & .005 & 1.072 & 1.021 & 1.126 \\
\hline
\end{tabular}


Table 8

Logistic Regression Prediction of Treatment Refusal Versus Treatment Compliance

95\% Confidence Intervals

$\begin{array}{llllll}\text { Predictor } & B & \text { S.E. Wald } & p & \text { Odds Ratio Lower Limit Upper Limit }\end{array}$

\begin{tabular}{lrrrrrrr} 
Childhood Abuse & 1.264 & .563 & 5.046 & .025 & 3.539 & 1.175 & 10.662 \\
$\mathrm{~L}$ & -.041 & .018 & 5.211 & .022 & .960 & .926 & .994 \\
\hline
\end{tabular}


Table 9

Logistic Regression Prediction of Treatment Non-Compliance Versus Treatment Compliance

95\% Confidence Intervals

$\begin{array}{llllll}\text { Predictor } & B & \text { S.E. } & \text { Wald } & p & \text { Odds Ratio Lower Limit Upper Limit }\end{array}$

\begin{tabular}{llllllll} 
Plea & 1.666 & .789 & 4.453 & .035 & 5.289 & 1.126 & 24.846 \\
\hline
\end{tabular}


Table 10

Correlations Among Study Variables

\begin{tabular}{|c|c|c|c|c|c|c|c|c|c|c|c|c|c|c|c|c|c|c|c|c|c|}
\hline & Age & Race & Edu. & Mar. & IQ & Read & Trail & Diag. & Treat. & Abuse & Viol. & Plea & Parole & Admit & VicAge & Gender & Relat. & Sex & Inc. & VRIN & $\mathrm{L}$ \\
\hline Race & .080 & & & & & & & & & & & & & & & & & & & & \\
\hline Education & .051 & .072 & & & & & & & & & & & & & & & & & & & \\
\hline Marital & $.413 * *$ & .257 & .055 & & & & & & & & & & & & & & & & & & \\
\hline IQ & -.050 & .025 & $.321 * *$ & .066 & & & & & & & & & & & & & & & & & \\
\hline Reading & .060 & .057 & $.333 * *$ & .086 & $.477^{* *}$ & & & & & & & & & & & & & & & & \\
\hline Trail B & .194 & .071 & $-.261 * *$ & .076 & $-.534 * *$ & $-.352 * *$ & & & & & & & & & & & & & & & \\
\hline Diagnosis & -.088 & $.269 * *$ & $-.192 *$ & .109 & -.005 & .036 & .111 & & & & & & & & & & & & & & \\
\hline Treatment & -.060 & $.178^{*}$ & $-.198^{*}$ & .016 & -.034 & .026 & .092 & $.568^{* * *}$ & & & & & & & & & & & & & \\
\hline Abused & -.064 & .022 & -.090 & .024 & .128 & -.035 & -.091 & -.021 & .096 & & & & & & & & & & & & \\
\hline Violent & -.182 & $.226 * *$ & -.125 & $.228 * *$ & -.022 & -.112 & $.026-$ & -.019 & .025 & .093 & & & & & & & & & & & \\
\hline Plea & -.096 & .125 & . 124 & 102 & .095 & .031 & -.074 & -.052 & -.020 & .018 & .078 & & & & & & & & & & \\
\hline Parole date & .036 & .085 & -.074 & .112 & -.142 & .004 & .154 & -.106 & .039 & -.137 & $.182 *-$ & -.033 & & & & & & & & & \\
\hline Admit & .039 & .047 & .003 & .036 & .030 & -.013 & .039 & -.064 & .092 & $.180^{*}$ & -.086 & $.269 * *$ & -.022 & & & & & & & & \\
\hline Victim age & .064 & $.174 *$ & $.206^{* *}$ & .083 & .098 & $.172 *-$ & $-.183^{*}$ & $-.233^{* *}$ & $-.223 * *$ & -.050 & $.214 * *$ & $* .014$ & -.014 & $-.231 * *$ & & & & & & & \\
\hline Gender & .037 & .028 & .019 & .037 & .019 & -.004 & -.039 & .025 & $-.176^{*}$ & -.148 & .018 & -.072 & -.002 & -.124 & $.249 * *$ & & & & & & \\
\hline Relation & $.278^{* *}$ & *.202* & .062 & $.312 * *$ & $* .049$ & -.081 & .006 & .084 & .022 & .091 & -.106 & .113 & -.091 & .046 & -.148 & .137 & & & & & \\
\hline Sex offense & .040 & .084 & .110 & .043 & $.174 *$ & .027 & -.065 & -.019 & .136 & .152 & .002 & .070 & -.007 & $.164^{*}$ & .072 & .072 & .013 & & & & \\
\hline Incarceration & -.169 & .002 & -.081 & $.212^{* *}$ & $* .000$ & $-.192 *$ & -.017 & $.209^{* * *}$ & *. .063 & -.057 & -.010 & .113 & -.040 & -.106 & .003 & .029 & -.126 & .356 *** & & & \\
\hline VRIN & .010 & .062 & -.120 & .062 & $-.210^{*}$ & $-.366^{* *}$ & $.208 *$ & .023 & .005 & .141 & -.039 & .017 & -.049 & .101 & $-.228^{* *}$ & * -.096 & .034 & -.047 & -.014 & & \\
\hline $\mathrm{L}$ & .049 & .037 & -.003 & .014 & -.125 & -.057 & -.060 & -.131 & $-.167 *$ & .111 & .080 & .035 & .030 & .068 & .051 & .085 & -.046 & -.139 & -.026 & -.051 & \\
\hline Mf & .129 & $.182 *$ & .142 & 136 & .106 & $.188^{*}$ & .013 & -.002 & .081 & $.273 * *$ & .058 & -.117 & .025 & .001 & -.036 & .015 & .113 & .129 & -.059 & $.199 *$ & $-.189 *$ \\
\hline
\end{tabular}

John

$\mathrm{H}$.

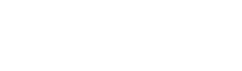

